\title{
Anthelmintic drugs and nematicides: studies in Caenorhabditis elegans*
}

\author{
Lindy Holden-Dye ${ }^{\S}$ and Robert J. Walker \\ Southampton Neuroscience Group (SoNG), Centre for Biological Sciences, University of \\ Southampton, Southampton SO17 1BJ, UK.
}

\section{Table of Contents}

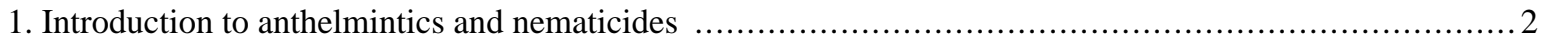

2. Is $C$. elegans a model 'parasite'? .................................................................... 3

3. Approaches for the study of anthelmintics and nematicides in C. elegans .................................. 4

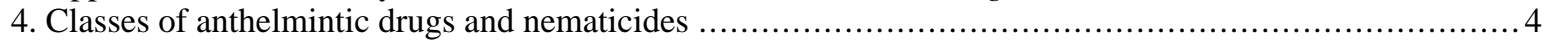

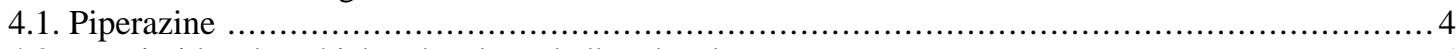

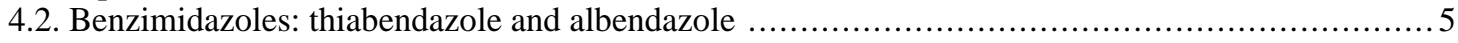

4.3. Imidazothiazole: levamisole, and tetrahydropyrimidines: pyrantel and morantel ..................5

4.4. Spiroindoles: paraherquamide and derquantel (2-deoxyparaherquamide/PNU 141962) $\ldots \ldots \ldots \ldots . . . .8$

4.5. Macrocyclic lactones; avermectins and milbemycins; ivermectin and moxidectin .................8

4.6. Cyclooctadepsipeptides: emodepside and PF1022A ...................................... 11

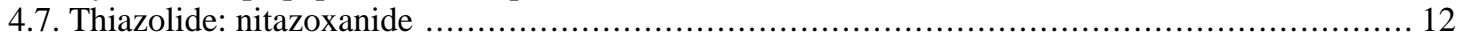

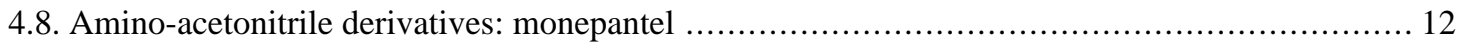

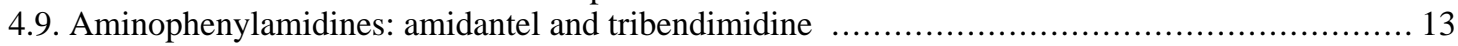

4.10. Crystal (Cry) proteins from Bacillus thuringiensis: Cry5B, Cry21A ........................... 14

4.11. Organophosphate and carbamate anticholinesterases: dichlorvos, haloxon, trichlorphon and

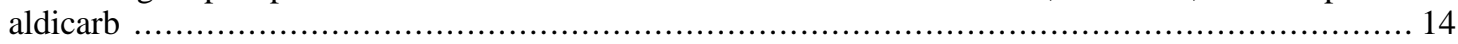

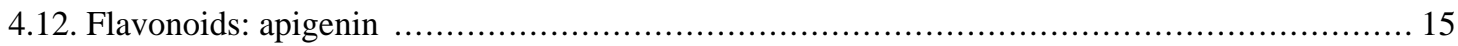

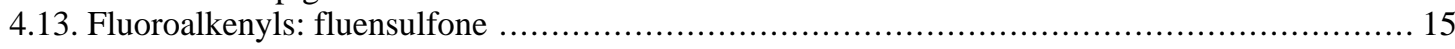

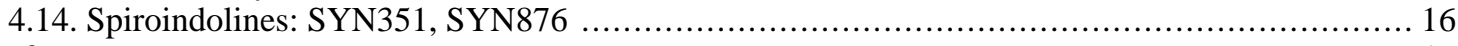

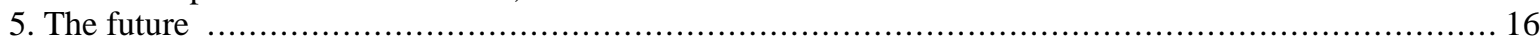

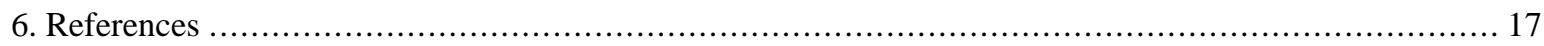

${ }^{*}$ Edited by Peter J. Roy. Last revised January 3, 2014. Published December 16, 2014. This chapter should be cited as: Holden-Dye L. and Walker R.J. Anthelmintic drugs and nematicides: studies in Caenorhabditis elegans (December 16, 2014), WormBook, ed. The C. elegans Research Community, WormBook, doi/10.1895/wormbook.1.143.2, http://www.wormbook.org.

Copyright: @ 2014 Lindy Holden-Dye and Robert J. Walker. This is an open-access article distributed under the terms of the Creative Commons Attribution License, which permits unrestricted use, distribution, and reproduction in any medium, provided the original author and source are credited.

${ }^{\S}$ To whom correspondence should be addressed. E-mail: 1mhd@soton.ac.uk 
Abstract

Parasitic nematodes infect many species of animals throughout the phyla, including humans. Moreover, nematodes that parasitise plants are a global problem for agriculture. As such, these nematodes place a major burden on human health, on livestock production, on the welfare of companion animals and on crop production. In the $21^{\text {st }}$ century there are two major challenges posed by the wide-spread prevalence of parasitic nematodes. First, many anthelmintic drugs are losing their effectiveness because nematode strains with resistance are emerging. Second, serious concerns regarding the environmental impact of the nematicides used for crop protection have prompted legislation to remove them from use, leaving agriculture at increased risk from nematode pests. There is clearly a need for a concerted effort to address these challenges. Over the last few decades the free-living nematode Caenorhabditis elegans has provided the opportunity to use molecular genetic techniques for mode of action studies for anthelmintics and nematicides. These approaches continue to be of considerable value. Less fruitful so far, but nonetheless potentially very useful, has been the direct use of $\boldsymbol{C}$. elegans for anthelmintic and nematicide discovery programmes. Here we provide an introduction to the use of $C$. elegans as a 'model' parasitic nematode, briefly review the study of nematode control using $C$. elegans and highlight approaches that have been of particular value with a view to facilitating wider-use of $C$. elegans as a platform for anthelmintic and nematicide discovery and development.

\section{Introduction to anthelmintics and nematicides}

Anthelmintic is the term used to describe a drug used to treat infections of animals with parasitic worms. This includes both flat worms, e.g., flukes (trematodes) and tapeworms (cestodes) as well as round worms (nematodes). The parasites are of huge importance for human tropical medicine and for veterinary medicine. The World Health Organization estimates that 2 billion people harbour parasitic worm infections (http://www.who.int/mediacentre/ factsheets/fs366/en/) causing increased morbidity and mortality, while parasitic worms that infect livestock are an important animal welfare issue and place a major economic burden on food production. Domestic pets are also susceptible to parasitic worm infection and it is of note that the companion animal market is a key economic consideration for animal health companies undertaking drug discovery programmes.

The majority of anthelmintics and nematicides are limited in their action between trematodes, cestodes, and nematodes, for example, praziquantel, a drug used in the treatment of most humans infected with trematodes or cestodes and thought to act by disrupting calcium homeostasis (Greenberg, 2005), has no activity against nematodes (see Table 1). Only benzimidazoles have cross-phyla activity and even then are more active against nematodes than against cestodes or trematodes.

Table 1. Key drugs registered for the treatment of parasitic worms in humans.

\begin{tabular}{|l|l|}
\hline Schistosomiasis (blood fluke) & Intestinal round worms \\
\hline Oxamnaquine & Piperazine \\
\hline Praziquantel & Benzimidazoles \\
\hline & Morantel \\
\hline Cestodiasis (tape worm) & Pyrantel \\
\hline Albendazole & Levamisole \\
\hline Niclosamide & Avermectins and milbemycins \\
\hline Benzimidazoles & Tribendimidine \\
\hline Praziquantel & \\
\hline Fasciolasis (liver fluke) & \\
\hline Triclabendazole & Filariasis (tissue round worms) \\
\hline & Diethylcarbamazine \\
\hline & Albendazole \\
\hline
\end{tabular}


Despite the prevalence of parasitic worms, anthelmintic drug discovery is the poor relation of the pharmaceutical industry. The simple reason is that the nations that suffer most from these tropical diseases have little money to invest in drug discovery or therapy. It comes as no surprise therefore that the drugs available for human treatment were first developed as veterinary medicines. There is thus a pitifully small repertoire of chemotherapeutic agents available for treatment (see Table 1). In some respects, this situation has been exacerbated by the remarkable success of ivermectin over the last thirty years (Geary, 2005), which has decreased motivation for anthelmintic drug discovery programmes (Geary et al., 1999). This prompts concern, as anthelmintic resistance has been widely reported in livestock and it may also only be a matter of time before this phenomenon also occurs widely in parasites of humans (Osei-Atweneboana et al., 2011; Churcher et al., 2009; Osei-Atweneboana et al., 2007).

Also of importance are species of nematode that infect plants. These plant parasitic nematodes cause major crop losses and are a threat to food security. Chemicals termed nematicides are used to protect crops from infestation. C. elegans has been used to provide insight into mechanisms for controlling these nematodes (Costa et al., 2009), albeit in a rather limited fashion to date. This review will also discuss the study of the action of the organophosphate and carbamate nematicides in C. elegans.

\section{Is C. elegans a model 'parasite'?}

Parasitic nematodes are very difficult to work with, requiring passage through their host for maintenance of their parasitic life-cycle. This greatly complicates quantitative experiments in their natural habitat. Methods for conducting forward and reverse genetics are also at best primitive. Thus C. elegans has routinely been exploited as a more 'user-friendly' model system that is also highly tractable to molecular genetic techniques. However, the life-style of the free-living worm C. elegans is very different to that of the parasites, and therefore parasitologists have given careful thought to its relevance (Holden-Dye and Walker, 2012; Geary and Thompson, 2001). In terms of overall 'body plan' there is no doubt that all the species in the phylum Nematoda exhibit similarity despite their very different habitats. More detailed consideration has been given to a comparison of the genetics, for example, the arrangement of the genome, synteny, and homology between specific genes (Mitreva et al., 2005). Overall, there would seem to be considerable molecular diversity between the different species in the phylum. It is probably safe to conclude that $C$. elegans is no more dissimilar to parasitic nematodes than each individual species of parasite is to another. Using $C$. elegans permits the application of powerful molecular genetic approaches and it has been extensively, and successfully, exploited as a model system to define molecular components of signalling pathways that underpin nematode physiology.

Indeed, it could be argued that the most relevant consideration for using $C$. elegans as a model to study anthelmintics and nematicides is the comparative physiology and pharmacology of the Nematoda. Most anthelmintics target the neuromusculature and therefore similarities here become of particular importance. The wiring diagram for the neuromuscular system is similar between C. elegans and the parasitic nematode Ascaris suum (Angstadt et al., 1989), as are the major neurotransmitters: acetylcholine in the excitatory motorneurons (Johnson and Stretton, 1985), GABA in the inhibitory motorneurons (Johnson and Stretton, 1987), and glutamate providing input onto the motorneurons (Davis, 1998). A striking feature of the pharmacology of the nematode nervous system is the abundance of neuropeptides. The majority, conceivably all, of $C$. elegans neurons express neuropeptides along with their classical neurotransmitters (for review see Li and $\mathrm{Kim}, 2010 ; \mathrm{Li}, 2005$ ). Many of these peptides have potent effects in parasitic nematodes, specifically on musculature which regulates vital nematode processes including feeding, locomotion, and egg-laying (Brownlee et al., 2000). Further evidence for an important functional role for peptidergic signalling has been provided by analysis of $C$. elegans mutants. In these studies mutants for the enzymes involved in the processing of neuropeptides, the proconvertase egl-3 (Kass et al., 2001) and carboxypeptidase egl-21 (Jacob and Kaplan, 2003), have been shown to be severely depleted in neuropeptide content (Husson et al., 2006) and to have phenotypes consistent with the idea that neuropeptides have modulatory roles within the neural networks that direct a range of important worm behaviours.

Neuropeptides are present throughout the animal phyla and also subserve pivotal roles in the nervous systems of the mammalian hosts of parasitic nematodes. However, neuropeptides, unlike the small molecule 'classical' transmitters, (e.g., acetylcholine), have diverged considerably in structure during evolution and this presents the promise that drugs targeting peptidergic signalling in nematodes may have low mammalian toxicity. There has thus been considerable interest in the prospect of developing peptidomimetics as a novel approach for nematode control. 
A comparative analysis of the neuropeptide content for a range of nematodes has been comprehensively reviewed (Marks and Maule, 2010; McVeigh et al., 2005) and may become an important consideration if this strategy is to be pursued. Progress has been made towards pairing the neuropeptide ligands with their cognate receptors in C. elegans (Frooninckx et al., 2012) and this may point to new molecular targets for nematode control.

A comparative analysis of the physiology and pharmacology of $C$. elegans with plant parasitic nematodes is more difficult as there is very little information available for these species in this regard. However, compared with most animal parasitic nematodes, plant parasitic nematodes are more amenable to maintenance in the laboratory. A recent review summarises the current knowledge concerning the plant parasitic nematodes and broadly speaking in terms of neurotransmitters there would appear to be good conservation with C. elegans (Holden-Dye and Walker, 2011) although the pharmacology of the respective neurotransmitter receptors has yet to be explored.

\section{Approaches for the study of anthelmintics and nematicides in C. elegans}

There is a large body of literature describing the study of bioactive compounds in C. elegans and the proposal to use it for the study of anthelmintics precedes the publication of the C. elegans genome sequence by nearly 20 years. Rand and Johnson (1995) coined the term 'genetic pharmacology' to describe this approach. These studies generally hinge on the ability of a drug to elicit a significant, ideally quantifiable, change in the worm's growth, development, metabolism, and/or behaviour. Pharmacokinetic considerations include the method and duration of drug exposure. For the vast majority of experiments the anthelmintics are applied to intact $C$. elegans. There are thus two ways in which the drug can gain access to target tissues, namely by ingestion or by diffusion across the cuticle. In this regard it should be noted that for many drugs the cuticle presents a significant permeability barrier. Thus the lipophilicity of drugs has a strong bearing on the concentration that is achieved in target tissues following external application. It is not uncommon for polar drugs to be applied at a concentration 1000 fold higher than their predicted affinity for the target. It may be possible to ameliorate this problem to some extent by employing animals that have a compromised cuticle (Gravato-Nobre et al., 2005). A number of possible strategies for overcoming C. elegans xenobiotic resistance and enhancing its value in identifying new anthelmintics have been reviewed recently by Burns and Roy (2012).

Once the effect of a particular drug on C. elegans has been defined, two different strategies may be adopted to investigate the molecular basis for its biological activity. The first follows a hypothesis-led approach in which strains with mutations in genes of known function are tested for altered sensitivity to the drug. The alternate strategy is to conduct a forward genetic screen. This is a powerful and objective approach that provides novel insight into the signalling pathways that mediate anthelmintic action. Often the impact of these studies extends beyond the interests of parasitologists and into the broader context of cellular and molecular neuroscience. This is because the vast majority of anthelmintics exert their effects in the neuromuscular system and key transduction molecules in the nervous system are highly conserved across the phyla from worm to human. Thus anthelmintic resistance screens can promote the discovery and characterisation of genes that have important roles in neurotransmission. An excellent example of the utility of this approach is provided by genetic screens employing the organophosphate cholinesterase inhibitors, in particular aldicarb which provides an excellent example of 'genetic pharmacology' and the interested reader is directed to Nguyen et al. (1995), Miller et al. (1996), and Sieburth et al. (2005).

\section{Classes of anthelmintic drugs and nematicides}

Anthelmintics and nematicides are separated into classes on the basis of similar chemical structure and mode of action. There are only a few main classes and each is briefly discussed in turn below. For the most part, information on the physiological and pharmacological actions of these compounds has been obtained from studies on the large parasitic nematode A. suum. C. elegans, on the other hand, has been valuable in defining molecular targets and downstream signalling cascades.

\subsection{Piperazine}

Piperazine was first used as an anthelmintic in the 1950s and it is still the active constituent of over the counter remedies for thread worm infection in children. Its mode of action has primarily been studied in A. suum where it acts as a weak GABA-mimetic and causes a flaccid, reversible paralysis of body wall muscle. Single channel recordings provide evidence that it is a low efficacy, partial agonist at GABA-gated chloride channels (Martin, 1985). Recently the action of piperazine has been investigated in C. elegans by comparing its action on wild type and mutants for unc-49, a gene which encodes C. elegans GABA -like receptor subunits expressed at the body wall 
neuromuscular junction (Miltsch et al., 2013). Although very high concentrations were required (50-100 $\mathrm{mM}$ ), piperazine had a similar inhibitory action on both wild type and unc-49 mutant animals. In a development assay for C. elegans, piperazine also had the same inhibitory effect on both wild type and unc-49 mutants. It is possible that piperazine does not interact with UNC-49 but may possibly interact with other putative GABA-gated chloride channel receptors identified in the C. elegans genome, for example, LGC-37, LGC-38, and GAB-1.

\subsection{Benzimidazoles: thiabendazole and albendazole}

The first of this class, thiabendazole, was discovered in 1961 and subsequently a number of further benzamidazoles were introduced as broad spectrum anthelmintics. There is an extensive literature on these compounds reporting a number of different biochemical effects. Nonetheless, it is clear that their anthelmintic efficacy is due to their ability to compromise the cytoskeleton through a selective interaction with $\beta$-tubulin (Borgers and de Nollin, 1975; for review see Lacey, 1990). The effects of benzimidazoles on C. elegans, which include impaired locomotion and reproduction, and a detrimental effect on oocytes, are consistent with disruption of processes requiring integral microtubules. The sensitivity of $C$. elegans to benzimidazoles is mediated by a single gene, ben-1, which encodes $\beta$-tubulin (Driscoll et al., 1989). This has provided a platform to investigate the molecular basis of benzimidazole resistance in parasitic nematodes. It has been noted that benzimidazole resistance in Haemonchus contortus seems to be associated with the presence of specific alleles for $\beta$-tubulin in the drug resistant isolates (Kwa et al., 1994). Whether or not a specific $\beta$-tubulin isoform could confer resistance to the drug was tested by experiments that showed that the sensitivity of $C$. elegans ben-1 mutants to benzimidazole can be rescued by expressing a $H$. contortus allele of $\beta$-tubulin from benzimidazole susceptible isolates, but cannot be rescued by the allele present in the resistant isolates (Kwa et al., 1995). This unequivocally demonstrated that a single amino acid substitution, $\mathrm{Y}$ for $\mathrm{F}$, in $\beta$-tubulin, can confer anthelmintic resistance. This is the first elegant example of a 'model hopping' approach in which the genetic tractability of $C$. elegans is directly exploited to define gene function for a parasitic worm. The relationship between $\beta$-tubulin genes in $H$. contortus and $C$. elegans is explored in greater detail in Saunders et al. (2013).

\subsection{Imidazothiazole: levamisole, and tetrahydropyrimidines: pyrantel and morantel}

These compounds have a broad-spectrum anthelmintic efficacy against nematodes but have no action against cestodes or trematodes. Tetramisole is a racemic mixture of $\mathrm{L}$ and $\mathrm{D}$ isomers, while levamisole is the pure $\mathrm{L}$-isomer. Pyrantel and morantel are structurally related to each other but different in structure from levamisole and are also effective anthelmintics.

Over 40 years ago it was shown that tetramisole (Aceves et al., 1970) and pyrantel (Aubry et al., 1970) both act as nicotinic receptor agonists and elicit spastic muscle paralysis due to prolonged activation of the excitatory nicotinic acetylcholine receptors (nAChRs) on body wall muscle of nematodes. Voltage-clamp studies using $A$. suum body wall muscle cells have shown that morantel, pyrantel, and levamisole mimic the actions of acetylcholine, with the following order of potency: morantel=pyrantel>levamisole>acetylcholine (Harrow and Gration, 1985). The reversal potential for all the compounds was around $+10 \mathrm{mV}$, indicating they all activate the same ion channels. These authors also found evidence that pyrantel and acetylcholine compete for the same receptor. Their precise mode of action has been carefully studied at the single-channel level on the body wall muscle preparation of $A$. suum (for review see Martin et al., 2005). Pharmacological analysis has provided evidence for subtypes of nACh receptor (Qian et al., 2006), an N-type (preferentially activated by nicotine), a B-type (preferentially activated by bephenium), and an L-type (preferentially activated by levamisole and associated with levamisole resistance).

Levamisole, and related compounds, also cause spastic paralysis and egg-laying in C. elegans. Thus $C$. elegans has provided an experimental platform to further investigate the molecular pharmacology of imidazothiazoles and tetrahydropyrimidines on nAChRs and some of this work will now be reviewed.

Forward genetic screens using levamisole have been extremely productive. Initially tetramisole was used (Brenner, 1974) but later this was replaced by levamisole (Lewis et al., 1980a). These screens have provided a resource of mutants that have been used over the last two to three decades to assign functions to genes expressed at the neuromuscular junction. Some of these are $\mathrm{nAChR}$ subunits but others interestingly are not and serve to either regulate nicotinic receptors or muscle function. A list of these genes is given in Table 2 together with their likely functions. 
Table 2. A summary of gene function for C. elegans levamisole resistant mutants.

\begin{tabular}{|c|c|c|}
\hline Gene & Function & Reference \\
\hline$u n c-38^{1}$ & $\alpha$-like nAChR subunit & Fleming et al., 1997 \\
\hline unc-29 & non $\alpha$-like nACh $\mathrm{R}$ subunit & Fleming et al., 1997 \\
\hline $\operatorname{lev}-1^{2}$ & non $\alpha$-like AChR subunit & Fleming et al., 1997 \\
\hline unc-63 & $\alpha$-like nAChR subunit & Culetto et al., 2004 \\
\hline$l e v-8(a c r-13)^{2}$ & $\alpha$-like nAChR subunit & Towers et al., 2005 \\
\hline unc- $22^{2}$ & twitchin & Moerman et al., 1988 \\
\hline unc-50 & $\begin{array}{l}\text { regulation of subtype specific nAChR trafficking to } \\
\text { cell surface }\end{array}$ & Boulin et al., 2008 \\
\hline unc- $-68^{2}$ & ryanodine receptor & Maryon et al., 1996 \\
\hline$l e v-9^{2}$ & secreted protein required for clustering of L-nAChRs & Culetto et al., 2004 Gendrel et al., 2009 \\
\hline$l e v-11^{2}$ & tropomyosin & Kagawa et al., 1995 \\
\hline$l e v-10^{2}$ & $\begin{array}{l}\text { transmembrane protein required for aggregation of } \\
\text { nAChRs }\end{array}$ & Gally et al., 2004 \\
\hline ric-3 & chaperone for receptor maturation & Halevi et al., 2002 \\
\hline oig-4 & stabilization and localization of L-nAChRs & Rapti et al., 2011 \\
\hline$n r a-1$ & $\begin{array}{l}\text { putative Ca-dependent phospholipid copine binding } \\
\text { protein }\end{array}$ & Gottschalk et al., 2005 \\
\hline $\operatorname{tax}-6$ & regulation of nAChR sensitivity to nicotine & Gottschalk et al., 2005 \\
\hline egl-15 & required for optimal nAChR levels & Gottschalk et al., 2005 \\
\hline soc-1 & required for optimal nAChR levels & Gottschalk et al., 2005 \\
\hline tpa-1 & role in nicotine adaptation of $\mathrm{nAChRs}$ & Waggoner et al., 2000 \\
\hline bath-42 & maintenance of optimal RIC-3 levels & Shteingauz, et al., 2009 \\
\hline unc-74 & $\begin{array}{l}\text { required for trafficking nAChR subunits to surface and } \\
\text { their correct folding }\end{array}$ & Boulin et al., 2008 \\
\hline molo-1 & $\begin{array}{l}\text { auxillary transmembrane subunit enhances channel } \\
\text { gating, no effect on unitary conductance }\end{array}$ & Boulin et al., 2012 \\
\hline$n r a-2 / 4$ & $\begin{array}{l}\text { control of nAChR subunit composition or ratio of } \\
\text { subunits }\end{array}$ & Almedom et al., 2009 \\
\hline$m i R-1$ & $\begin{array}{l}\text { muscle-specific microRNA, regulation of expression } \\
\text { level of UNC-29 and UNC-63 }\end{array}$ & Simon et al., 2008 \\
\hline
\end{tabular}


Levamisole is more potent than acetylcholine at contracting cut preparations of C. elegans, inducing contraction at low $\mu \mathrm{M}$ concentration (Ruiz-Lancheros et al., 2011; Lewis et al., 1980b). In intact animals, the EC for levamisole-induced paralysis is $9 \mu \mathrm{M}$ (Qian et al., 2008). The work of Fleming et al. (1997) provided evidence for the role of UNC-38, UNC-29, and LEV-1 as subunits of the nAChR of C. elegans. Until this work, eleven genes had been identified that conferred levamisole resistance (Lewis et al., 1987; Lewis et al., 1980b; Brenner, 1974). Extreme resistance to levamisole was shown by the following mutants: lev-1, unc-29, unc-38, unc-63, unc-74, and unc-50; partial resistance was seen in mutants to lev-8, lev-9, lev-10, unc-22, and unc-11 (the latter two classified as twitchers). Whole-cell voltage-clamp experiments using $C$. elegans ventral body wall muscle cells revealed evidence for two nAChRs, a levamisole-sensitive receptor requiring both unc-38 and unc-29 genes for activity, and a receptor activated by both nicotine and acetylcholine present in unc-38 and unc-29 mutants that underwent rapid desensitization (Richmond and Jorgensen, 1999). They concluded that the N- (nicotinic sensitive) and L(levamisole sensitive) AChRs contributed about equally to the acetylcholine current of C. elegans body wall muscle. These results clearly demonstrate that levamisole has a direct excitatory effect on body wall muscle, which represents at least one of the sites for the anthelmintic action of levamisole. Subsequent work in which AChR subunits were expressed in Xenopus laevis oocytes demonstrated that five subunits were required for a functional receptor: lev-1, lev-8, unc-29, unc-38, and unc-63, together with three ancillary factors: ric-3, unc-50, and unc-74 (Boulin et al., 2008). This receptor combination responded to both acetylcholine and levamisole, but not to nicotine, which acted as an antagonist. The removal of any of the subunits greatly reduced the responses to both compounds. Interestingly, when these authors expressed acr-16 together with ric-3 in Xenopus oocytes they obtained large currents to acetylcholine and nicotine but levamisole failed to induce a current. A number of ancillary factors have been shown to play a role in the assembly and functioning of L-nAChRs (Table 2). One of these, MOLO-1, physically interacts with the L-nAChR to increase gating and so is a true auxiliary transmembrane subunit (Boulin et al., 2012). MOLO-1 interacts with L-nAChRs at an early stage in the secretory pathway and co-localizes with the receptor at the neuromuscular junction. However, it does not interact with N-nAChRs. Another factor, miR-1, regulates both the sensitivity of muscle cells to acetylcholine through the expression level of UNC-29 and UNC-63, and the amount of acetylcholine released from presynaptic neurons via a retrograde messenger, MEF-2 (Simon et al., 2008).

Embryonic cells grown from a primary culture developed into L1 C. elegans muscle cells and these were used for single channel recordings from nAChRs (Rayes et al., 2007). These nAChRs were levamisole sensitive and showed a single population of channels with a conductance of $39 \mathrm{pS}$ which was five times more sensitive to levamisole than to acetylcholine. The presence of UNC-38, UNC-63, and UNC-29 subunits was essential for channel activity. Interestingly, lev-1 mutants had a channel conductance of $26 \mathrm{pS}$, with prolonged open duration but were less sensitive to levamisole. This shows that L-nAChRs can still function in L1 muscle cells in the absence of LEV-1. Using this preparation, single channel currents could also be activated by pyrantel and morantel. The relative potencies of the agonists tested were morantel=pyrantel $>$ levamisole $>$ acetylcholine, the same order of potency as found by Harrow and Gration (1985) using A. suum body wall muscle and voltage-clamp recordings. In a later paper (Hernando et al., 2012) it was shown that LEV-8 is not essential for functional L-nAChRs, though lev-8 mutants showed kinetic changes in the channel properties and were less sensitive to levamisole. These authors also showed that while ACR-8 is not required for wild-type L-nAChRs, it can replace LEV-8 in lev-8 mutants. The lev-8; acr- 8 double mutant is strongly resistant to levamisole. Since no gene corresponding to lev- 8 has been found in several trichostrongylid species it is possible that acr-8 replaces lev-8 in these parasitic nematodes (Neveu et al., 2010). Qian et al. (2008) have also made single channel recordings from C. elegans body wall muscle. In these experiments they used lev-10 mutants in which aggregation of nAChRs is absent, allowing recordings from single channels. The mean conductance for these channels was around $30 \mathrm{pS}$ when activated by either levamisole or acetylcholine. These levamisole-activated channels were insensitive to nicotine. These authors found that $l e v-8$; lev-10 double mutants expressed fewer channels, which also had a smaller mean conductance of $26.9 \mathrm{pS}$. These authors review the value of the $C$. elegans levamisole receptor as a model for parasitic nematodes and note that while $C$. elegans has levamisole-activated channels ranging from 26-36 pS, those in A. suum range from 18-53 pS (Qian et al., 2006; Levandoski et al., 2005). The reader is referred to an in-depth review relating levamisole research using $C$. elegans to research using parasitic nematodes by Martin et al. (2012b). Another review compares the nAChRs of C. elegans with those of parasitic nematodes (Holden-Dye et al., 2013).

Levamisole does not activate N-nAChRs in $C$. elegans though it does act as an antagonist at these receptors (Ballivet et al., 1996). Dihydro- $\beta$-erythroidine also distinguishes between L- and N-nAChRs, acting as an antagonist at N-nAChRs but has a very weak blocking effect at L-nAChRs (Richmond and Jorgensen, 1999). In contrast to the L-nAChR, the N-nAChR is a homomer composed of five ACR-16 subunits and probably accounts for all non-levamisole-sensitive nicotinic synaptic events at the neuromuscular junction (Touroutine et al., 2005). There is 
evidence that CWN-2 (a Wnt ligand), LIN-17, and CAM-1 (Ror receptor tyrosine kinase) are all involved in controlling the translocation of ACR-16 receptors (Jensen et al., 2012; Francis et al., 2005). A neuronal acetylcholine receptor has also been identified in C. elegans and has the following composition: UNC-38, UNC-63, ACR-2, ACR-2, and ACR-12 (Jospin et al., 2009). When expressed in Xenopus oocytes this receptor is almost completely insensitive to levamisole and only weakly activated by nicotine, but the effect of acetylcholine is clearly blocked by mecamylamine. For expression in oocytes, it was necessary to co-inject unc-50, unc-74, and ric-3, in addition to the five cholinergic subunits.

In summary, C. elegans has provided a useful platform to investigate the molecular pharmacology of these classes of compounds and in turn these anthelmintics continue to provide important pharmacological tools to dissect subtypes and the stoichiometry of native nematode nicotinic receptors.

\subsection{Spiroindoles: paraherquamide and derquantel (2-deoxyparaherquamide/PNU 141962)}

Paraherquamide A and marcfortine A are both members of the oxindole alkaloid family, originally isolated from Penicillium paraherquei and P. roqueforti, respectively (Zinser et al., 2002). Their chemistry, efficacy, and mode of action have been reviewed (Lee et al., 2002). A specific, high affinity binding site for paraherquamide has been identified in a membrane preparation isolated from C. elegans, with an apparent Kd of $263 \mathrm{nM}$ (Schaeffer et al., 1992). Paraherquamide and its derivative, 2-deoxy-paraherquamide (derquantel), induce flaccid paralysis in parasitic nematodes in vitro. Pharmacological analysis of the effects of these drugs on acetylcholine-stimulated body wall muscle contractions in A. suum muscle strips in vitro has shown that they act as typical competitive antagonists, shifting the concentration-response curves to the right in a parallel fashion (Robertson et al., 2002). These drugs have no apparent direct effect on A. suum body wall muscle tension or membrane potential (Lee et al., 2002). Paraherquamide also blocks the actions of other nicotinic agonists, but not equipotently (Robertson et al., 2002; Zinser et al., 2002). Interestingly, this antagonist seems to distinguish nicotinic receptor subtypes on the muscle, and has a greater affinity for the receptors mediating the response to levamisole and pyrantel than the receptors that mediate the response to nicotine. Patch-clamp recording from A. suum body wall muscle has found at least three subtypes of nAChRs based on conductance, namely, N, L, and B, with conductances of 22/24 pS, 33/35 pS, and 45 pS, respectively (Qian et al., 2006). Confirming previous studies, paraherquamide failed to antagonize the $\mathrm{N}$ (nicotine-sensitive) subtype, the L (levamisole-sensitive) subtype was antagonized by paraherquamide, and the B (bephenium-sensitive) subtype was antagonized more by 2-deoxyparaherquamide than by paraherquamide. Using a cut preparation of $C$. elegans, 2-deoxyparaherquamide has been shown to paralyse $C$. elegans and to antagonize the actions of bephenium in preference to pyrantel and, to a lesser extent, levamisole on this preparation; that is, bephenium>pyrantel>levamisole, suggesting a preference for B subtype nAChRs (Ruiz-Lancheros et al., 2011). 2-Deoxyparaherquamide only antagonized $10 \mu \mathrm{M}$ nicotine and so it was difficult to compare sensitivity of nicotine to 2-deoxyparaherquamide in relation to the other nicotinic agonists. Deoxyparaherquamide appeared to be more potent as an antagonist compared to mecamylamine. These authors raised the possibility that the cuticle of $C$. elegans may be less permeable than the cuticles of parasitic nematodes, which might influence the value of $C$. elegans as a primary screen for anthelmintics.

Importantly, the mode of action of this class of anthelmintics differs from the more established drugs that interfere with cholinergic transmission (e.g., levamisole) in that they act as competitive antagonists rather than cholinomimetics. The use of paraherquamide in forward genetic screens has not yet been reported but could potentially generate interesting new mutants. As it is a competitive inhibitor of the body wall nACh receptor, it would be predicted that mutations that increase transmitter release should confer resistance. Thus a forward genetic screen might reveal further negative regulators of neurotransmitter release. For a review that covers the discovery, mode of action, and use of 2-deoxyparaherquamide in combination with abamectin as the anthelmintic, Startect, see Woods et al. (2012).

\subsection{Macrocyclic lactones; avermectins and milbemycins; ivermectin and moxidectin}

Ivermectin was introduced as an anthelmintic in the 1980s by Merck. It is a semi-synthetic derivative of avermectin which is a large macrocyclic lactone fermentation product of the micro-organism Streptomyces avermitilis. It is remarkably potent $(\sim 1 \mathrm{nM})$ and persistent in its effect, and its discovery enthused other companies to invest in the development of ivermectin analogues which include moxidectin, milbemycin oxime, doramectin, selamectin, abamectin, and eprinomectin. Here C. elegans played a role, as it was employed in a screen for further macrocyclic lactones with ivermectin-like activity (Haber et al., 1991). 
Ivermectin elicits a potent and persistent paralysis of nematode pharyngeal (Pemberton et al., 2001; Brownlee et al., 1997) and body wall musculature (Kass et al., 1982; Kass et al., 1980). It has been shown to interact with a range of ligand-gated ion channels including $\alpha 7 \mathrm{nACh}$ receptors (Krause et al., 1998), acetylcholine-gated chloride channels (Bokisch and Walker, 1986), GABA-gated chloride channels (Holden-Dye and Walker, 1990; Robertson, 1989), histamine-gated chloride channels (Zheng et al., 2002), glycine receptors (Shan et al., 2001), and P2X4 receptors (Khakh et al., 1999). However, it is its high affinity for nematode glutamate-gated chloride channels $(\mathrm{GluCl})$ that correlates with its potent anthelmintic activity. This was defined by the team at Merck that succeeded in expression cloning GluCl $\alpha$ and GluCl $\beta$ ion channel subunits from C. elegans (Cully et al., 1994). Both subunits were expressed either singly or together in Xenopus oocytes. GluCl $\alpha$ responds to micromolar ivermectin but not to glutamate, while GluCl $\beta$ responds to glutamate but not ivermectin. Co-expression of GluCl $\alpha$ and GluCl $\beta$ yields a channel which responds to glutamate and is positively allosterically modulated by nanomolar ivermectin. Subsequently a small family of nematode genes encoding $\mathrm{GluCl}$ channels has been identified (for review see Yates et al., 2003). The nomenclature is confusing as the same genes have been discovered by both homology screening approaches and from forward genetic screens for ivermectin resistance genes. Essentially there are four $C$. elegans genes encoding GluCl $\alpha$ subunits, two of which are alternately spliced yielding the GluCl channels: GluCl $\alpha 1$ encoded by $g l c-1$, GluCl $\alpha 2 \mathrm{~A}$ and B encoded by $a v r-15$, GluCl $\alpha 3 \mathrm{~A}$ and B encoded by $a v r-14$, and GluCl$\alpha 4$ encoded by $g l c-3$, (Table 3 ). There is just one GluCl $\beta$ subunit encoded by $g l c-2$, and a further gene, $g l c-4$, which is divergent from the genes encoding $\alpha$ and $\beta$ subunits. Although the pharmacology of channels assembled from these $\mathrm{GluCl}$ subunits has been defined in heterologous expression systems, the important question of the subunit stoichiometry and pharmacology of the native channels is much more poorly defined. Further studies on $C$. elegans are providing a better understanding of this by delineating the expression pattern for $\mathrm{GluCl}$ subunits in the nervous system. For example, the pharyngeal muscle expresses avr-15 and glc-2 (Dent et al., 1997; Laughton et al., 1997). Thus it might be expected that GluCl $\alpha 2$ and GluCl $\beta$ subunits co-assemble to form a native ivermectin-sensitive channel. Whether or not other subunits contribute to the functional receptor is not yet clear. However, the pharyngeal muscle of $a v r-15$ mutants does not respond to ivermectin (Pemberton et al., 2001; Dent et al., 1997), clearly indicating an involvement of GluCl $\alpha 2$. An important point to note in terms of the site of anthelmintic action of ivermectin is that although the pharynxes of avr-15 mutants are not inhibited by ivermectin, populations of avr-15 mutants exposed to ivermectin are still paralyzed. Thus GluCl channels in the pharynx are not required for the paralytic effect. This may also be true for parasitic nematodes. For example, ivermectin has anthelmintic activity against Ascaridia galli and yet the pharynx of this species is not inhibited by the drug (Holden-Dye and Walker, 2006).

Table 3. A summary of glutamate-gated chloride receptor subunits and their expression in C. elegans.

\begin{tabular}{|c|c|c|c|}
\hline Subunit & Gene & Expression & Reference \\
\hline GluCl $\alpha 1$ & $g l c-1$ & $\begin{array}{l}\text { intestine, pharyngeal and body wall } \\
\text { muscle, head neurons }\end{array}$ & Dent et al., 2000 \\
\hline GluCL $\alpha 2 A, B$ & $a v r-15$ & $\begin{array}{l}\text { pharyngeal muscle (pm4 and 5), head } \\
\text { neurons, including RMED, RMEV, } \\
\text { RMGs, weak stain in sublateral nerve } \\
\text { cords and some mechanosensory } \\
\text { neurons. }\end{array}$ & Dent et al., 1997 \\
\hline GluCL $\alpha 3 A, B$ & $a v r-14$ & $\begin{array}{l}\text { neurons in ring ganglion, ventral cord, } \\
\text { and some mechanosensory neurons. }\end{array}$ & Dent et al., 2000 \\
\hline GluCl $\alpha 4$ & $g l c-3$ & AIY interneuron & Wenick and Hobert, 2004 \\
\hline \multirow[t]{2}{*}{ GluCl $\beta$} & $g l c-2$ & pharyngeal muscle pm4 & Laughton et al., 1997 \\
\hline & $g l c-4$ & $\begin{array}{l}\text { intestine, anal depressor muscle, head } \\
\text { mesodermal cell, nerve ring, head and } \\
\text { tail neurons }\end{array}$ & $\begin{array}{l}\text { M. Pellegrino and J. Dent, personal } \\
\text { communication }\end{array}$ \\
\hline
\end{tabular}

In order to obtain a better understanding of the role of $\mathrm{GluCl}$ channels in mediating the paralytic actions of ivermectin it is probably most informative to consider their role in the motornervous system. Currently most information is available for avr-14 and avr-15. These genes are expressed in the motor nervous system of C. elegans (Dent et al., 2000; Dent et al., 1997) and there is immunostaining for GluCla3A and B in motorneurons of the 
parasitic nematode H. contortus (Portillo et al., 2003). One role of these $\mathrm{GluCl}$ channels in C. elegans involves regulation of the duration of forward movement, a well established glutamatergic-regulated behaviour (see Ionotropic glutamate receptors: genetics, behavior and electrophysiology). This function may be conserved between C. elegans and H. contortus as H. contortus GluCla3 subunits expressed in C. elegans avr-14 mutants restore the wild-type pattern of movement (Cook et al., 2006). It is most likely that the paralytic action of ivermectin derives from its potent activation of $\mathrm{GluCl}$ in the motor nervous system of nematodes. However, the precise role of individual $\mathrm{GluCl}$ channels in mediating the effects of ivermectin on these circuits is yet to be established. The mechanism of resistance to ivermectin has also been studied in C. elegans. High level resistance is a complex phenomenon which requires mutations in at least three genes: glc-1, avr-14, and avr-15. Further genes, regulating membrane permeability (osm-1) and gap junctions (unc-7 and unc-9), are also involved (Dent et al., 2000). Defining the role of $\mathrm{GluCl}$ mutations in conferring ivermectin resistance to parasitic nematodes in the field is a less tractable and more controversial problem (Wolstenholme et al., 2004).

Ivermectin has been found to interact with AVR-14 subunits located in the muscle layer of the excretory-secretory apparatus of Brugia malayi microfilariae (Moreno et al., 2010). In vitro treatment of the microfilariae with ivermectin reduced the proteins released by the excretory-secretory apparatus. It is proposed that in vivo the lack of these proteins no longer allows the microfilariae to overcome the host's immune system and so they are rapidly eliminated from the host.

C. elegans has been used to study ivermectin resistance, which may involve changes in P-glycoprotein (members of the ABC transporter superfamily, for review see Ardelli, 2013) activity. Increased expression of $p g p$ genes resulted in increased resistance to ivermectin (James and Davey, 2009), while loss-of-function of individual Pglycoproteins resulted in enhanced susceptibility to ivermectin (Ardelli and Prichard, 2013; Janssen et al., 2013). In their study, James and Davey (2009) exposed C. elegans to increasing concentrations of ivermectin. Increased resistance was associated with increased expression of multidrug-resistance protein and P-glycoprotein genes. Strains that showed resistance to ivermectin also showed resistance to moxidectin, levamisole, and pyrantel, but not to albendazole. Inactivation of $p g p-1,-5,-6,-12$, and -13 all produced enhanced sensitivity to ivermectin (Ardelli and Prichard, 2013). These genes are primarily expressed in the intestine, pharynx and amphids. Ardelli and Prichard (2013) suggest there are multiple avenues for the action of ivermectin.

In an attempt to identify differences between the mode of action of ivermectin and moxidectin, Ardelli et al. (2009) have investigated their actions on pharyngeal pumping, development, and locomotion in wild type and glutamate-gated chloride channel mutants in C. elegans. The results are summarized in Table 4, from which it can be seen there are differences between the two anthelmintics. While the activity of both anthelmintics is lost in the absence of AVR-14, AVR-15, and GLC-1, it is notable that $g l c-2$ mutants showed increased motility when $2.5 \mathrm{nM}$ moxidectin was applied during the first 90 minutes, an effect not observed with ivermectin. The glc-2 mutant's pharyngeal pumping was equally sensitive to both ivermectin and moxidectin whereas in the wild type moxidectin was $>10$ times less active compared to ivermectin. In general, glc-4 mutants were more sensitive to both anthelmintics.

Table 4. Differential actions of ivermectin and moxidectin on C. elegans. A comparison of the concentrations (in $\mathrm{nM}$ ) of ivermectin and moxidectin required to arrest larval development, motility, and pharyngeal pumping in wild-type and glutamate-gated chloride channel mutants (after Ardelli et al. 2009).

\begin{tabular}{|l|l|l|l|l|l|l|}
\hline Strain & Larval development & Motility & \multicolumn{2}{l|}{ Pharyngeal pumping } \\
\hline & ivermectin & moxidectin & ivermectin & moxidectin & ivermectin & moxidectin \\
\hline Wild type & 0.61 & 39.0 & 19.5 & 39.0 & 4.9 & 78 \\
\hline avr-14:avr-15: glc-1 & $>5000$ & $>5000$ & $>5000$ & $>5000$ & $>5000$ & $>5000$ \\
\hline glc-2 & 39.0 & 2500 & 170 & 310 & 9.8 & 9.8 \\
\hline glc-3 & 19.5 & 5000 & 9.8 & 19.5 & 4.9 & 19.5 \\
\hline glc-4 & 2.4 & 19.5 & 2.4 & 4.9 & 2.4 & 9.8 \\
\hline
\end{tabular}

Information concerning the binding of ivermectin and its activation mechanism has advanced with the publication of the crystal structure of ivermectin bound to the C. elegans homomeric pentamer $\alpha$ GluClR (Lynagh and Lynch, 2012; Hibbs and Gouaux, 2011). Ivermectin binds at the transmembrane domain interface of two 
adjacent subunits, wedged between M3 from the principal subunit (M3(+)) and M1 from the complementary subunit (M1(-)). Thus ivermectin re-arranges the transmembrane domain helical organization in order to open the channel. This structural change induced by ivermectin to open the channel pore is different from that induced by glutamate (Lynagh and Lynch, 2012). Studies such as these on C. elegans are providing a deeper insight into the mode of action of this important class of anthelmintic.

One of the macrocyclic lactones, abamectin, has also been found to be useful as a nematicide and is marketed as a seed treatment (Avicta) to protect plants from invasion from plant parasitic nematodes. Presumably, extrapolating from C. elegans, abamectin exerts its action through plant parasitic nematode glutamate-gated chloride channels but this has not yet been studied.

\subsection{Cyclooctadepsipeptides: emodepside and PF1022A}

The cyclooctadepsipeptide molecule, emodepside, is a semi-synthetic derivative of PF1022A, a fermentation product obtained from the fungus, Mycelia sterilia, of Camelia japonica. Its discovery and anthelmintic activity is described in Harder and von Samson-Himmelstjerna (2002) and has been reviewed recently (Krucken et al., 2012). It is effective against isolates of parasites that are resistant to benzimidazole, levamisole, and ivermectin indicating, importantly, that it has a novel mode of action. The molecule has pore-forming properties in planar lipids, however, this does not appear to be important in conferring its anthelmintic potency as an optical isomer of emodepside, with similar pore forming properties, does not have anthelmintic action. Thus it would appear that it may act through stereospecific binding to a receptor. Studies in A. suum have highlighted muscle paralysis and point to a calciumand potassium-dependent mechanism of action (Willson et al., 2003). A candidate receptor for the cyclodepsipeptides has been cloned from an $H$. contortus cDNA library by immunoscreening with an antibody to PF1022 A. This receptor, designated HC110R, has been expressed in HEK293 cells and shown to gate calcium flux in a PF1022 A-dependent manner (Saeger et al., 2001). It has homology to mammalian latrophilins, a class of G protein-coupled receptors which bind the neurotoxin, latrotoxin. Latrotoxin paralyses mammals by triggering neurotransmitter release, and thus the identification of latrophilin as an emodepside receptor raised the intriguing possibility that emodepside may cause paralysis of nematodes by stimulating excessive neurotransmitter release at neuromuscular sites.

C. elegans is very susceptible to the effects of emodepside at nanomolar concentrations (Bull et al., 2007). The effects include slowed development, inhibition of pharyngeal pumping, decreased locomotion (forward movement is most affected at low concentrations), and inhibition of egg-laying leading to 'bagging' in adult hermaphrodites. Thus $C$. elegans has provided an excellent model in which to define the molecular target, or targets, through which emodepside exerts its pleiotropic actions and indeed, to test whether latrophilins are involved.

There are two genes encoding candidate latrophilins in C. elegans, lat-1 and lat-2. The role of these latrophilins in mediating the inhibitory effects of emodepside on feeding and locomotion has been investigated using RNAi and gene knockouts (Bull et al., 2007; Guest et al., 2007; Willson et al., 2004). The pharyngeal system of lat-1 mutants shows a reduced sensitivity to emodepside but their locomotor activity is inhibited in a similar fashion to wild-type animals (Guest et al., 2007). Emodepside does not exert its inhibitory effect on locomotion through the other latrophilin, LAT-2, as lat-2 mutants respond just like wild-type animals. Nor is there redundancy of function between LAT-1 and LAT-2 in terms of the effect of emodepside on locomotion, as the double mutant lat-2; lat-1 responds to emodepside in a similar fashion to the single mutant, lat-1 (Guest et al., 2007). Clearly, emodepside has latrophilin-independent actions.

Forward genetic screens have provided further insight into the mechanism through which emodepside exerts its inhibitory action on C. elegans muscle (Guest et al., 2007). A chemical mutagenesis screen of twenty thousand genomes for mutants that could move and propagate on micromolar emodepside recovered nine alleles of a single gene, slo-1. Strains carrying functional null alleles of slo-l are highly resistant to the inhibitory effects of emodepside on locomotion and feeding. Furthermore, strains carrying gain-of-function alleles of slo- 1 behave in a similar manner to emodepside-treated animals but are not themselves emodepside hypersensitive. These data strongly support the contention that emodepside activates a SLO-1-dependent pathway to bring about neuromuscular inhibition.

SLO-1 is a calcium-activated potassium channel (Wang et al., 2001) homologous to the mammalian BK channels. Thus the discovery of SLO-1 as an important effector for emodepside resonates with earlier work on Ascaris muscle which showed a calcium and potassium-dependent hyperpolarisation (Willson et al., 2003). This channel is highly conserved throughout the animal phyla and plays a pivotal role in regulating neuronal and muscle 
cell excitability (for review, Salkoff et al., 2006). In C. elegans it is widely expressed in the nervous system and body wall muscle, but not in pharyngeal muscle. By expressing a wild-type copy of $s l o-1$ in specific subsets of cells in a slo- 1 null background it has been shown that emodepside can inhibit locomotor activity when SLO-1 is present in neurons or body wall muscle (Guest et al., 2007).

Since BK channels occur widely in animals, including host species for nematodes, the effect of emodepside on C. elegans, where the native SLO-1 channels had been replaced by a mammalian orthologue, the human KCNMA1 channel, was investigated (Crisford et al., 2011). C. elegans slo-1 mutants display certain behavioural deficits and these were restored when kcnmal was expressed in these mutants, indicating that KCNMA1 channels can function in C. elegans. Animals expressing kcnmal in place of slo-l were 10 to 100 times less responsive to emodepside. Interestingly, body bends of $C$. elegans expressing kcnmal were reduced in the presence of both NS 1619 and rottlerin (mallotoxin), both agonists of mammalian BK channels (Zakharov et al., 2005; Olesen et al., 1994), but neither compound had any effect on wild-type $C$. elegans. Crisford et al. (2011) also investigated the effect of emodepside on $C$. elegans slo- 1 mutants where $s l o-1$ was ectopically expressed in pharyngeal muscle. Normally slo-1 is not expressed in pharyngeal muscle at detectable levels but is selectively expressed in pharyngeal neurons (Chiang et al., 2006; Wang et al., 2001). Further experiments showed that when wild-type slo- 1 was selectively expressed in the pharyngeal muscle of $C$. elegans slo- 1 mutants emodepside inhibited pharyngeal pumping, providing further evidence for SLO-1 being a major target for emodepside in C. elegans. The interaction between SLO-1 channel genes from Ancylostoma caninum and Cooperia oncophora and emodepside expressed in C. elegans has also been investigated (Welz et al., 2011). When slo- 1 from A. caninum and $C$. oncophora were expressed in $C$. elegans slo- 1 mutants, their sensitivity to emodepside was restored, providing evidence that emodepside can act on SLO-1 channels from parasitic nematodes and for $C$. elegans as an excellent model for such expression studies. In addition, these authors showed that penitrem A, an inhibitor of BK channels (Knaus et al., 1994), blocked the effect of emodepside in C. elegans, providing further evidence for SLO-1 channels as the site of emodepside's action in nematodes. Assuming the main target for emodepside is SLO-1, the question arises as to whether emodepside activates or inhibits SLO-1 actions. Preliminary data would suggest that emodepside facilitates activation of SLO-1 channels heterologously expressed in HEK293 cells (Holden-Dye et al., 2012). A recent review summarises research on emodepside and the value of $C$. elegans in elucidating its mode of action (Krucken et al., 2012).

The discovery of SLO-1 as a mediator of the inhibitory effects of emodepside on C. elegans is an important development in this field, which in the light of ivermectin resistance has an urgent need for such breakthroughs. In the broader context, there is an emerging body of evidence indicating that BK channels such as SLO-1 may play a pivotal role in conferring sensitivity to neuroactive drugs, including ethanol and local anaesthetics (Dillon et al., 2013; Hawasli et al., 2004; Davies et al., 2003), and in regulating the pattern of activity of neural networks (Salkoff et al., 2006). Thus, an additional and valuable facet of these studies is that emodepside provides a new tool to dissect the functional role of SLO-1 in neural networks using the power of molecular genetics in C. elegans. Recent reviews summarise the evidence for SLO-1 as the major target site for emodepside in C. elegans and parasitic nematodes (Holden-Dye at al., 2012; Martin et al., 2012a). Current evidence would suggest that emodepside acts on both latrophilin receptors and SLO-1 channels in the pharyngeal system to inhibit pumping but only on SLO-1 channels in body wall muscle to inhibit locomotion.

\subsection{Thiazolide: nitazoxanide}

Nitazoxanide, a pyruvate:ferredoxin oxidoreductase inhibitor, acts against a broad spectrum of protozoa and helminths that occur in the intestinal tract. The enzyme it targets is required to maintain electron transfer during anaerobic respiration. It is currently used for the treatment of protozoal infections (and is therefore not listed in Table 1). The site of action of this compound has not been established in nematodes although anaerobic electron transport enzymes may be a potential target (Gilles and Hoffman, 2002). The effect of nitazoxanide has been examined on growth and development of C. elegans (Fonseca-Salamanca et al., 2003). After seven days culture nitazoxanide $(100 \mu \mathrm{M})$ only reduced population growth by $33 \%$. In contrast mebendazole $(5 \mu \mathrm{M})$ and albendazole $(1$ $\mu \mathrm{M})$ reduced growth by over $90 \%$. Nitazoxanide $(100 \mu \mathrm{M})$ had no effect on either embryonation or hatching in Heligmosomoides polygyrus. Therefore the efficacy of this compound is relatively low compared to other anthelmintic agents. Nitazoxanide also failed to show much activity against Trichuris muris or Ancylostoma ceylanicum in vivo (Tritten et al., 2012). Nitazoxanide has been found to inhibit ATP synthesis in C. elegans (Hemphill et al., 2006).

\subsection{Amino-acetonitrile derivatives: monepantel}

During investigations for new anthelmintics acting through novel sites, the amino-acetonitrile derivatives (AADs) were identified using a larval development assay against a benzimidazole-resistant isolate of $H$. contortus 
Ducray et al., 2008). These authors noted that while $\mathrm{N}$-acyl amino-acetonitriles had been used against insects, fungi and bacteria, they had not previously been tested against nematodes. Subsequent research showed the AADs were active against a range of nematodes, including various stages of Cooperia oncophora, Trichostrongylus colubriformis, Ostertagia ostertagi, Nematodirus spathiger, Teladorsagia circumcincta, and Chabertia ovina (Kaminsky et al., 2008a). After testing a number of AADs for their anthelmintic activity, including their efficacy and tolerability in sheep and cattle, AAD-1566 was selected for in depth study in sheep and given the name, monepantel (Kaminsky et al., 2008b; Kaminsky and Rufener, 2012). The AADs were effective against nematodes that had shown resistance to levamisole, ivermectin and/or albendazole (Kaminsky et al., 2008a). Monepantel is also more effective as an anthelmintic compared to derquantel in combination with abamectin when sheep were treated with a multi-resistant $H$. contortus isolate (Sager et al., 2012).

A forward genetic screen for amino-acetonitrile resistance, using C. elegans mutants, identified two possible genes, acr-17 and acr-23, both members of the DEG-3 group of nicotinic receptor subunits in C. elegans (Kaminsky et al., 2008a). ACR-23, and not ACR-17, was identified as the main contributor to the AAD response of hypercontraction of body wall muscle and paralysis, that is, acting as an acetylcholine agonist. Interestingly, the DEG-3 group of nicotinic subunits is not present in mammals (Mongan et al., 2002) consistent with the observation that monepantel is well tolerated by the host. Further screens in H. contortus were conducted to identify the molecular target in the parasitic nematodes. Three H. contortus lines were identified that were resistant to AADs, all of which carried mutations in a gene encoding the nicotinic ACh receptor subunit, Hco-des-2H (Kaminsky et al., 2008a). However, a C. elegans mutant lacking the homologous receptor subunit, DES-2, was not resistant to AADs. Two of these H. contortus lines also carried mutations in Hco-acr-23H, which is now called Hco-mptl-1 (Rufener et al., 2009). This raises the question as to the role of these subunits in mediating the anthelmintic action of monepantel. The pharmacology of the subunits, Hco-deg-3 and Hco-des-2, was investigated in more detail through expression in Xenopus oocytes, and interestingly a heteromer of these subunits was found to be more sensitive to choline than to acetylcholine (Rufener et al., 2010a). Monepantel and monepantel sulfone, the major metabolite of monepantel in sheep (Karadzovska et al., 2009) both enhanced the choline-induced currents, thus indicating that they act as positive allosteric modulators of these channels. Rufener et al. (2010a) were unable to express Hco-mptl-1 in Xenopus oocytes, perhaps because the HcoMPTL-1 receptor requires a specific chaperone and/or additional AChR subunits for functionality; therefore, direct evidence that this subunit is sensitive to monepantel is lacking. Nonetheless, there is further evidence for ACR-23/MPTL-1 subunit as the primary target for monepantel as when this subunit is absent in a nematode, for example, Pristionchus pacificus or Strongyloides ratti, these species are relatively insensitive to monepantel (>100 times less sensitive compared to C. elegans) (Rufener et al., 2010b). The monepantel story from its discovery to mode of action has been summarized recently (Kaminsky and Rufener, 2012) and a comparison of the properties of monepantel, emodepside and derquantel has also recently been published (Epe and Kaminsky, 2013).

\subsection{Aminophenylamidines: amidantel and tribendimidine}

Over 30 years ago amidantel (Bayd 8815) was introduced as a new anthelmintic against hookworms, $A$. caninum and Unicinaria stencephala (Thomas, 1979). Amidantel and its derivatives, including tribendimidine, were later synthesized in China and studied for biological activity (Xiao et al., 2013; Xiao et al., 2005). Tribendimidine was particularly active against Ascaris lumbricoides and Necator americanus. In an attempt to identify the site of action of tribendimidine a forward genetic screen for tribendimidine resistant mutants was undertaken using $C$. elegans (Hu et al., 2009). Wild-type C. elegans were paralyzed when exposed to $220 \mu \mathrm{M}$ tribendimidine and closer inspection indicated degeneration of their internal structure. The development of L1 larvae in this concentration was also delayed. In their screen, Hu et al. (2009) identified ten resistant animals that they divided into four groups, trb-1, trb-2, trb-3, and trb-4. These mutants had normal brood sizes in the presence of tribendimidine while wild-type C. elegans had reduced brood size. Hu et al. (2009) found that tribendimidine mutants were also resistant to levamisole and pyrantel, indicating that tribendimidine resistant $C$. elegans were also resistant to L-subtype $\mathrm{nAChR}$ agonists suggesting a common target for tribendimine and levamisole, the L-nAChR. Moreover, they found that $t r b-1$ to -4 correlated to genes already identified for levamisole resistance: unc-63, lev-8, unc-50, and unc-22, respectively. In addition, it was shown that tribendimidine resistance occurred in eleven further levamisole-resistant mutants. The action of tribendimidine in C. elegans mutants lacking components of the L-nAChR has been investigated (Miltsch et al., 2013) where unc-38, unc-63, lev-1, or lev-8 mutants had greatly reduced sensitivity to the anthelmintic, demonstrating the importance of all these subunits for tribendimidine action. Thus using C. elegans it has been shown that tribendimidine and levamisole act at the same receptor and so nematodes resistant to levamisole would also be predicted to be resistant to tribendimidine. Levamisole is listed as an anthelmintic for use in humans (WHO Model List of Essential Medicines, 2013) but is rarely used in practice due to its low therapeutic index. 


\subsection{Crystal (Cry) proteins from Bacillus thuringiensis: Cry5B, Cry21A}

Cry proteins are pore-forming proteins made by the Gram-positive bacterium, Bacillus thuringiensis (Hu and Aroian, 2012a; Hu and Aroian, 2012b). Though first used as insecticides, these compounds have since been shown to have anthelmintic properties, including against $C$. elegans (Kotze et al., 2005; Wei et al., 2003). When Cry5B is fed to $C$. elegans there is damage to its intestine, a fall in brood size from around 250 to 5, and death (Marroquin et al., 2000). These authors developed a genetic screen for recovery of mutants resistant to Cry5B. The mutants were called bre mutants, Bacillus-toxin resistant, and five genes were identified, bre-1, -2, $-3-4$ and -5 . The intestine of all five mutants was unaffected by Cry5B while the bre mutants were strongly resistant to Cry5B-induced death. The effect of Cry5B on brood size was also greatly reduced in these mutants. The same group in a later paper cloned bre-1 and characterized its phenotype (Barrows et al., 2007). bre-1 encodes an enzyme with homology to GDP-mannose 4,6-dehydratase which is involved in the synthesis of GDP-fucose. Injection of GDP-fucose into intestinal cells of $C$. elegans rescues the bre-1 phenotype. These mutants also show defects in the production of polar glycolipids which act as receptors for Cry5B (Griffiths et al., 2005). These carbohydrates contain the arthroseries core which is present in nematodes but absent in vertebrates (Hu and Aroian, 2012b). Cry protein monomers bind to intestinal cell receptors, oligomerize, and enter the plasma membrane to form pores. These holes in the membrane disrupt cell integrity, ionic balance, and membrane potentials, resulting in death or severe disruption of cell activity. So far, all nematodes tested, whether they are free-living, animal, or plant parasites, are sensitive to Cry5B. In an interesting study it has been shown that combination therapy of Cry5B and $n A C h R$ agonists may have potential as the combination exhibits synergistic properties (Hu et al., 2010). In C. elegans the p38 mitogen activated protein kinase (MAPK) pathway protects against Cry5B (Kao et al., 2011). A similar situation has been found in hookworms, for example, A. ceylanicum ( $\mathrm{Hu}$ et al., 2012a), demonstrating that $C$. elegans is likely to be a good model for the study of these toxins in nematodes.

\subsection{Organophosphate and carbamate anticholinesterases: dichlorvos, haloxon, trichlorphon and aldicarb}

Anticholinesterases block the enzymes that break down the neurotransmitter acetylcholine. Thus adminstration of the compounds leads to elevation of synaptic levels of acetycholine at the neuromuscular junction in nematodes and results in spastic paralysis. However, these compounds are highly toxic to all organisms that use acetylcholine as a neurotransmitter, including humans, and this severely limits their use. They have been used as nematicides against plant parasitic nematodes, but their toxicity is now prompting their withdrawal from use, even as chemical control agents for crop protection, because of serious environmental concerns. Here we will briefly discuss investigation of these compounds in C. elegans and highlight possible areas for future improvements.

Organophosphates and carbamates, acting through phosphorylation and carbamylation of the enzyme active site, respectively, have been the main cholinesterase inhibitors used as anthelmintics (Selkirk et al., 2005). In general organophosphates are not selective to nematode cholinesterases and so have a low therapeutic index and have largely been replaced by anthelmintics less toxic to the host. However, in recent studies on pyridinic compounds as potential anthelmintics, one compound, diethyl 2,2'-[(3-nitropyridine-2,6-diyl) bissulfanediyl] diacetate, which was effective as an anticholinesterase anthelmintic, was non-toxic in rats at a dose of $2000 \mathrm{mg} / \mathrm{kg}$ (Valli et al., 2011). Therefore, pyridinic compounds together with pyrazinics, may provide future safer cholinesterase inhibitors with high therapeutic indices.

Cholinesterases occur widely in animals, including nematodes, and have been studied in detail in C. elegans. Eighteen aldicarb- and trichlorphon-resistant genes have been characterized in C. elegans (Nguyen et al., 1995). These include cha-1, ric-1, -3, -4, snt-1 (ric-2) and ten unc mutants. Subsequently, four distinct acetylcholinesterase genes, viz, ace-1 (class A), ace-2 (class B), ace-3 (class C), and ace-4 have been identified in C. elegans (Grauso et al., 1998). Expression patterns of these genes have been investigated by Combes et al. (2003). ace-1 is expressed in all body wall muscle and vulval muscle cells, ace-2 in neurons (including amphid neuron AWC), ace-3; ace-4 operon in pharyngeal muscle cells, pm3, pm4, pm5, and pm7, a few head and ganglion neurons and in CANs. Interestingly, pm5 pharyngeal muscle cells express ace-1, ace-2, and ace-3 but otherwise these genes have their own expression patterns, indicating lack of redundancy.

Several papers have investigated the effect of organophosphates on gene expression in C. elegans (Lewis et al., 2013; Vinuela et al., 2010; Jadhav and Rajini, 2009; Lewis et al., 2009). Using sublethal concentrations of dichlorvos, 5-80 $\mu \mathrm{M}$, and four hours exposure, Jadhav and Rajini (2009) found that pharyngeal pumping and acetylcholinesterase activity were inhibited. The $\mathrm{LD}_{50}$ for dichlorvos decreased as exposure time was increased 
from 4 to $36 \mathrm{~h}$. When exposed to $5-80 \mu \mathrm{M}$ dichlorvos for between 4 and $3 \mathrm{~h}$, induction of the heat shock protein, hsp-16, increased both with concentration and time, with a maximum after $24 \mathrm{~h}$ and then induction declined. The induction of $h s p-16$ was confined to the pharynx. These studies showed that sub-lethal concentrations of an organophosphate can affect feeding, acetylcholinesterase activity, and expression of a stress gene. Induction of hsp-16 in C. elegans has been used as a monitor of environmental stress (Stringham and Candido, 1994). In their study, Vinuela et al.(2010) exposed C. elegans eggs for a total of $72 \mathrm{~h}$ to chlorpyrifos $(0.5 \mathrm{mg} / \mathrm{L}, \mathrm{approx}$. $1.4 \mu \mathrm{M})$ or diazinon $(1.0 \mathrm{mg} / \mathrm{L}$, approx. $3.3 \mu \mathrm{M})$ or a mixture of the two organophosphates. They found that 551 genes were regulated by chlorpyrifos, 245 by diazinon, with 126 regulated by either compound. 233 genes were regulated by the mixture, including 89 genes which were not regulated by the compounds alone. It is interesting that though the structures of the two organophosphates are similar, many of the genes they induced are different. These genes are involved in a number of pathways associated with detoxification (involving both phases I and II of xenobiotic metabolism), stress, innate immunity, and transport and metabolism of lipids. Vinuela et al. (2010) noted that while the effects on gene expression of the mixture of the two organophosphates showed differences from the effects of the single compounds, the pathways affected were similar, involving daf-16, elt-2, snk1/pmk-1, and sma-9. In their first paper Lewis et al. (2009) exposed L4 stage C. elegans to the organophosphates dichlorvos (3-50 mg/L, approx. 13.5-226 $\mu \mathrm{M})$ or fenamiphos (10-200 mg/L, approx. 33-660 $\mu \mathrm{M}$ ) or to the antimalarial mefloquine $(26-1300 \mu \mathrm{M}$ ) (as a control) for $8 \mathrm{~h}$. The expression of 87 genes was affected by exposure to the organophosphates but not to mefloquine while the abundance of 34 proteins also changed. Many of these genes and proteins were expressed in muscle and neuronal tissue and play a role in lipid metabolism, cell adhesion, apoptosis and detoxification. As in the study of Vinuela et al. (2010), some of the genes whose expression was altered were selective for one or the other organophosphate. In the second paper, Lewis et al. (2013) initially investigated the effect of a range of concentrations $(0.12-15.0 \mu \mathrm{M})$ of dichlorvos on $C$. elegans behaviour. $0.6 \mu \mathrm{M}$ and $15.0 \mu \mathrm{M}$ were selected for the gene expression study, and L3/ L4 animals exposed for 2 or $8 \mathrm{~h}$ or continuously during the experiment. A large number of the genes expressed following exposure to dichlorvos were transcriptionally regulated by DAF-16 which is associated with the control of metabolism, aging, innate immunity and stress responses in C. elegans. Dichlorvos activated similar genes to those activated by bacterial infections in C. elegans, which are involved in innate immunity. Dichlorvos also upregulated genes required for myogenesis, and for axon regeneration ( $d l k-1$ and pmk-3) and guidance. Genes associated with immune response and energy metabolism were upregulated within 2 h. Lewis et al. (2013) also looked for genes involved in recovery from dichlorvos and identified T19C4.5 and $h s p-16.41$, which were expressed following removal of dichlorvos. Seven key genes were identified that were upregulated by dichlorvos; unc-43, tir-1, sek-1, flp-18, sma-4, sma-6, and ins-7. They concluded that the main mechanisms for dichlorvos effects are the inhibition of acetylcholinesterase and depletion of energy reserves, possibly due to mitochondrial dysfunction. However, it is clear from these studies that, in addition to manipulating acetylcholine levels, organophosphates can act on a range of physiological processes in C. elegans, and by analogy also in parasitic nematodes.

\subsection{Flavonoids: apigenin}

C. elegans has been used to screen flavonoids for anthelmintic activity. In a study involving 13 flavones, apigenin was found to inhibit larval growth (Yoon et al., 2006). When the first generation developed in the presence of apigenin there was a slight reduction in body size but larval development in the F1 generation was severely impaired in the presence of the flavone. The mechanism associated with this inhibition of larval growth in $C$. elegans was investigated by Kawasaki et al. (2010) and found to be associated with DAF-16 activation. These authors proposed that apigenin acts as a stressor to either stimulate DAF-16 activity directly or inhibit DAF-2/insulin signalling, which reduces the inhibitory effect of DAF-2 on DAF-16. In either case DAF-16 is activated which leads to larval arrest. Flavone (2-phenyl chromone) has been shown to induce embryonic and larval lethality in both $C$. elegans and a plant parasitic nematode, the pinewood nematode, Bursaphelenchus xylophilus (Lee et al., 2008).

\subsection{Fluoroalkenyls: fluensulfone}

Fluensulfone (5-chloro-2-(3,4,4-trifluorobut-3-enylsulfonyl)-1,3-thiazole) is a member of the fluoroalkenyl thioether group and has proven potential as a new nematicide to control plant parasitic nematode infections (Oka et al., 2012; Oka et al., 2009). For example, application of fluensulfone through both soil drenching and foliar spray has been shown to significantly reduce root infection and penetration by plant parasitic nematodes, Meloidogyne javanica (Oka et al., 2009) and $M$. incognita (Oka et al., 2012). Fluensulfone has marked effects on the development and behaviour of $C$. elegans and the profile of its effects is different from the other main classes of anthelmintic and nematicides including levamisole, ivermectin, and the organophosphates, suggesting a distinct mode of action (Kearn et al., 2014). 


\subsection{Spiroindolines: SYN351, SYN876}

Spiroindolines have both insecticidal and anthelmintic activity, with SYN351 being the lead compound for studies using $C$. elegans (Sluder et al., 2012). SYN351 induces an uncoordinated "loopy", coiling locomotion in $C$. elegans, and also inhibits pharyngeal pumping frequency. cha-1 mutants, which have a defect in their ability to synthesise acetylcholine, are hypersensitive in the presence of the spiroindoline SYN876 while sublethal doses of SYN876 suppress the effect of the cholinesterase inhibitor, aldicarb. These experiments suggest that spiroindolines exert their effects on nematode behaviour by effectively reducing the levels of available acetylcholine at the synapse. A chemical mutagenesis screen employing C. elegans generated mutants which were resistant to spiroindolines. These resistant strains harboured mutations in the gene encoding the vesicular acetylcholine transporter (VAChT), unc-17 (Sluder et al., 2012), providing evidence that UNC-17 might be the target for the compound. Further studies, in which the vesicular acetylcholine transporter from Drosophila was expressed in PC12 cells, demonstrated a spiroindoline binding site that could be displaced by the classical acetylcholine vesicular transport inhibitor vesamicol. Taken together these data are consistent with the proposal that mutations in unc-17 confer C. elegans resistance to spiroindolines. Therefore spiroindolines are a group of compounds which appear to target a novel site for anthelmintic action, namely the vesicular acetylcholine transporter (Sluder et al., 2012).

\section{The future}

A particular challenge for companies engaged in anthelmintic and nematicide research, not experienced to the same extent by the pharmaceutical industry, is that cost-effectiveness is a prime concern. Moreover, there are additional constraints in terms of the levels of host toxicity that can be tolerated. For example, in tropical medicine, anthelmintics must be used in mass chemotherapy programmes in regions where clinical support is sparse, and therefore drugs need to be very well tolerated in humans of all ages. In treatment of livestock, persistence of chemicals in tissues becomes an issue for meat production, while the use of nematicides for crop protection has to take into careful consideration stability, leaching from the soil, and environmental toxicity, especially effects on non-target organisms.

As can be seen from the discussion above, only a relatively small repertoire of drugs and chemicals are currently available to address these needs. Notably, ivermectin has been hugely successful both in veterinary and tropical medicine, and its use in Africa has transformed the lives of populations previously devastated by the tropical disease onchocerciasis (river blindness). However, in the last five years resistance to ivermectin has been emerging (Osei-Atweneboana et al., 2011) and it is highly likely that successors will soon be needed for this extremely important anthelmintic.

There has been recent progress in drug and chemical development for the control of parasitic nematodes. Since 2007 three new anthelmintics have been used in the formulation of commercially available treatments; emodepside (Profender ${ }^{\circledR}$ spot-on for cats and tablets for dogs, Procox ${ }^{\circledR}$ for puppies), monepantel (Zolvix ${ }^{\circledR}$ for sheep), and derquantel (Starect ${ }^{\circledR}$ for sheep). Whether or not these anthelmintic drugs can be used in formulations to address further parasitic nematode infections of livestock and humans, or indeed whether they have efficacy or provide new leads to address the problem of plant parasitic nematodes, remains to be seen. The introduction of these anthelmintics and their current limited use has recently been concisely discussed by Epe and Kaminsky (2013). Emodepside has efficacy against filarial nematodes and compounds of this class may prove to be of use in the future for the treatment of filariasis (Olliaro et al., 2011; Zahner et al., 2001). There are also further possibilities in the pipeline. For example, closantel (a salicylanilide) has potential to treat onchocerciasis (Gloeckner et al., 2010). Closantel is an inhibitor of filarial chitinase which results in inhibition of moulting in infective L3 larvae of Onchocerca volvulus. However, this stage of the parasite is only briefly present in the host, and in addition closantel acts as a protonophore and is an uncoupler of oxidative phosphorylation (Skuce and Fairweather, 1990), both of which may limit this compound's usefulness. Nonetheless a number of closantel analogues have also been synthesized and tested for activity on $O$. volvulus (Garner et al., 2011).

As we have noted in this review, C. elegans has played a major role in defining the mode of action for anthelmintics and nematicides and can also contribute to understanding mechanisms of resistance, especially through the adoption of a 'model-hopping' approach whereby the functionality of parasite genes is assessed by using C. elegans as an expression system. The utility of this approach will be facilitated by progress in the sequencing and characterisation of parasite genomes. Noteworthy in this regard is the recent publication of a draft genome of MHCO3(ISE).N1, an inbred $H$. contortus strain that is susceptible to all the major anthelmintics, and its comparison to the genome of $C$. elegans (Laing et al., 2013). The pentameric ligand-gated ion channels of $H$. contortus are very 
similar to those of $C$. elegans, suggesting the value of $C$. elegans as a model for the Strongylid nematode nervous system. However, there are important gene differences in relation to glutamate, acetylcholine, and amine signalling. Laing et al. (2013) was followed by a second paper on the genome and developmental transcriptome of H. contortus (Schwarz et al., 2013).

An interesting extension of the model hopping approach is in the development of vaccines against parasitic nematodes, in which $C$. elegans can be used for the expression of vaccine antigens (Knox, 2012; Murray et al., 2007).

Of likely importance for the future is the use of $C$. elegans as a model system for drug discovery. It is to be hoped that this will provide new anthelmintics that have novel modes of action and thus circumvent the problem of anthelmintic resistance. The combination of RNAi and high throughput techniques for analysis of C. elegans stimulated interest in drug discovery using chemical genetic screens (Behm et al., 2005; Jones et al., 2005). Advances in the application of microfluidic- and droplet-based approaches to the study of $C$. elegans, and the incorporation of optogenetics, has extended this capability; a variety of 'chips' have been designed that facilitate imaging, behavioural analysis, and electrophysiology (Hu et al., 2013; Kearn et al., 2013; Liu et al., 2013; Lockery et al., 2012; Xu and Kim, 2011; Stirman et al., 2010; Ben-Yakar et al., 2009; Hulme et al., 2008; Chronis et al., 2007). The molecular targets for the drugs that come out of these screens or from other pipe-lines can be defined using the powerful approach of forward genetics in C. elegans, and may uncover new effectors for anthelmintic action.

More targeted approaches to anthelmintic drug discovery are also ongoing. These are providing fundamental information on nematode neurobiology with the aim of identifying signalling molecules that have pivotal roles in neural circuits that underpin vital behaviours. In this context the nematode nervous system still has target sites, such as ion channels and receptors, which have not yet been exploited and can form the basis for novel anthelmintics (Wolstenholme, 2011). It will be interesting to see whether or not the ambition to target peptidergic signalling pathways translates into a marketable drug (Geary and Maule, 2010; Greenwood et al., 2005), although the industry is actively investigating the characterization of FLP receptors from C. elegans (Larsen et al., 2013). However, to date there has been little success (Geary, 2012; McVeigh et al., 2012). There are also numerous enzymes involved in signalling and metabolic pathways that might provide novel sites for anthelmintic action, together with nematode amine receptors (Rana and Misra-Bhattacharya, 2013; Geary, 2012).

In conclusion, as discussed here and further emphasized elsewhere (Epe and Kaminsky, 2013; Olliaro et al., 2011), there is an urgent need to develop novel anthelmintics in view of the increasing threat to live-stock and humans from anthelmintic-resistant strains of parasites. C. elegans has proved to be an extremely useful model organism for mode of action studies, however, the opportunity it presents for drug discovery has arguably been under-utilised (see 'Bridging the Divide'; Worm Breeder's Gazette Volume 19, Number 4). An additional concern is the threat to crops from plant parasitic nematodes, as currently available nematicides are progressively withdrawn from use due to their environmental impact. For the future, C. elegans research should be further applied to these important challenges for human and veterinary medicine and for food security.

Acknowledgments: We are grateful to two anonymous reviewers for helpful comments which improved this manuscript.

\section{References}

Aceves, J., Erlij, D., and Martinez-Maranon, R. (1970). The mechanism of the paralysing action of tetramisole on Ascaris somatic muscle. Br. J. Pharmacol. 38, 602-607. Abstract Article

Almedom, R.B., Liewald, J.F., Hernando, G., Schultheis, C., Rayes, D., Pan, J., Schedletzky, T., Hutter, H., Bouzat, C., and Gottschalk, A. (2009). An ER-resident membrane protein complex regulates nicotinic acetylcholine receptor subunit composition at the synapse. EMBO J. 28, 2636-2649. Abstract Article

Angstadt, J.D., Donmoyer, J.E., and Stretton, A.O. (1989). Retrovesicular ganglion of the nematode Ascaris. J. Comp. Neurol. 284, 374-388. Abstract Article

Ardelli, B.F. (2013). Transport proteins of the ABC systems superfamily and their role in drug action and resistance in nematodes. Parasitol. Int. 62, 639-46. Abstract Article 
Ardelli, B.F., and Prichard, R.K. (2013). Inhibition of P-glycoprotein enhances sensitivity of Caenorhabditis elegans to ivermectin. Vet. Parasitol. 191, 264-275. Abstract Article

Ardelli, B.F., Stitt, L.E., Tompkins, J.B., and Prichard, R.K. (2009). A comparison of the effects of ivermectin and moxidectin on the nematode Caenorhabditis elegans. Vet. Parasitol. 165, 96-108. Abstract Article

Aubry, M.L., Cowell, P., Davey, M.J., and Shevde, S. (1970). Aspects of the pharmacology of a new anthelmintic: Pyrantel. Br. J. Pharmacol. 38, 332-344. Abstract Article

Ballivet, M., Alliod, C., Bertrand, S., and Bertrand, D. (1996). Nicotinic acetylcholine receptors in the nematode Caenorhabditis elegans. J. Mol. Biol. 258, 261-269. Abstract Article

Barrows, B.D., Haslam, S.M., Bischof, L.J., Morris, H.R., Dell, A., and Aroian, R.V. (2007). Reistance to Bacillus thuringiensis toxin in Caenorhabditis elegans from loss of fucose. J. Biol. Chem. 282, 3302-3311. Abstract Article

Behm, C.A., Bendig, M.M., McCarter, J.P., and Sluder, A.E. (2005). RNAi-based discovery and validation of new drug targets in filarial nematodes. Trends Parasitol. 21, 97-100. Abstract Article

Ben-Yakar, A., Chronis, N., and Lu, H. (2009) Microfluidics for the analysis of behavior, nerve regeneration, and neural cell biology in C. elegans. Curr. Opin. Neurobiol. 19, 561-567. Abstract Article

Bokisch, A.J., and Walker, R.J. (1986). The action of Avermectin (MK 936) on identified central neurons from Helix and its interaction with acetylcholine and gamma-aminobutyric acid (GABA) responses. Comp. Biochem. Physiol. C. 84, 119-125. Abstract Article

Borgers, M., and De Nollin, S. (1975). Ultrastructural changes in Ascaris suum intestine after mebendazole treatment in vivo. J. Parasitol. 61, 110-122. Abstract Article

Boulin, T., Gielen, M., Richmond, J.E., Williams, D.C., Paoletti, P., and Bessereau, J.L. (2008). Eight genes are required for functional reconstitution of the Caenorhabditis elegans levamisole-sensitive acetylcholine receptor. Proc. Natl. Acad. Sci. U. S. A. 105, 18590-18595. Abstract Article

Boulin, T., Rapti, G., Briseno-Roa, L., Stigloher, C., Richmond, J.E., Paoletti, P., and Bessereau, J.L. (2012). Positive modulation of Cys-loop acetylcholine receptor by an auxillary transmembrane subunit. Nat. Neurosci. 15, 1374-1381. Abstract Article

Brenner, S. (1974). The genetics of Caenorhabditis elegans. Genetics 77, 71-94. Abstract

Brockie, P.J., and Maricq, A.V. (2006). Ionotropic glutamate receptors: genetics, behavior and electrophysiology, WormBook, ed. The C. elegans Research Community, WormBook, doi/10.1895/wormbook. 1.61.1, http://www.wormbook.org.

Brownlee, D.J., Holden-Dye, L., and Walker, R.J. (1997). Action of the anthelmintic ivermectin on the pharyngeal muscle of the parasitic nematode, Ascaris suum. Parasitology 115, 553-561. Abstract Article

Brownlee, D., Holden-Dye, L., and Walker R.J. (2000). The range and biological activity of FMRFamide-related peptides and classical neurotransmitters in nematodes. Adv. Parasitol. 45, 109-180. Abstract Article

Bull, K., Cook, A., Hopper, N.A., Harder, A., Holden-Dye, L., and Walker, R.J. (2007). Effects of the novel anthelmintic emodepside on the locomotion, egg-laying behaviour and development of Caenorhabditis elegans. Int. J. Parasitol. 37, 627-636. Abstract Article

Burns, A.R., and Roy, P.J. (2012). To Kill a Mocking Worm: Strategies to improve Caenorhabditis elegans as a model for use in anthelmintic discovery. In Parasitic Helminths: Targets, Screens, Drugs and Vaccines, C.R. Caffrey, ed. (Weinheim, Germany: Wiley-VCH Verlag GmbH \& Co. KGaA), pp. 201- 216. Abstract Article

Chiang, J.T., Steciuk, M., Shtonda, B., and Avery, L. (2006). Evolution of pharyngeal behaviours and neuronal functions in free-living soil nematodes. J. Exp. Biol. 209, 1859-1873. Abstract Article 
Chronis, N., Zimmer, M., and Bargmann, C.I. (2007). Microfluidics for in vivo imaging of neuronal and behavioral activity in Caenorhabditis elegans. Nat. Methods. 4, 727-731. Abstract Article

Combes, D., Fedon, Y., Toutant, J-P., and Arpagaus, M. (2003). Multiple ace genes encoding acetylcholinesterases of Caenorhabditis elegans have distinct tissue expression. Eur. J. Neurosci. 18, 497-512. Abstract Article

Churcher, T.S., Pion, S.D., Osei-Atweneboana, M.Y., Prichard, R.K., Awadzi, K., Boussinesq, M., Collins, R.C., Whitworth, J.A., Basáñez, M.G. (2009). Identifying sub-optimal responses to ivermectin in the treatment of River Blindness. Proc. Natl. Acad. Sci. U. S. A. 106, 16716-21. Abstract Article

Cook, A., Aptel, N., Portillo, V., Siney, E., Sihota, R., Holden-Dye L., and Wolstenholme, A. (2006). Caenorhabditis elegans ivermectin receptors regulate locomotor behaviour and are functional orthologues of Haemonchus contortus receptors. Mol. Biochem. Parasitol. 147, 118-125. Abstract Article

Costa, J.C., Lilley, C.J., Atkinson, H.J., and Urwin, P.E. (2009). Functional characterisation of a cyst nematode acetylcholinesterase gene using Caenorhabditis elegans as a heterologous system. Int. J. Parasitol. 39, 849-858. Abstract Article

Crisford, A., Murray, C., O’Connor, V., Edwards, R.J., Kruger, N., Welz, C., von Samson-Himmelstjerna, G., Harder, A., Walker R.J, and Holden-Dye, L. (2011). Selective toxicity of the anthelmintic emodepside revealed by heterologous expression of human KCNMA1 in Caenorhabditis elegans. Mol. Pharmacol. 79, 1031-1043. Abstract Article

Culetto, E., Baylis, H.A., Richmond, J.E., Jones, A.K., Fleming, J.T., Squire, M.D., Lewis, J.A., and Sattelle, D.B. (2004). The Caenorhabditis elegans unc-63 gene encodes a levamisole-sensitive nicotinic acetylcholine receptor $\alpha$ subunit. J. Biol. Chem. 279, 42476-42483. Abstract Article

Cully, D.F., Vassilatis, D.K., Liu, K.K., Paress, P.S., Van der Ploeg, L.H., Schaeffer, J.M., and Arena, J.P. (1994). Cloning of an avermectin-sensitive glutamate-gated chloride channel from Caenorhabditis elegans. Nature 371, 707-711. Abstract Article

Davies, A.G., Pierce-Shimomura, J.T., Kim, H., VanHoven, M.K., Thiele, T.R., Bonci, A., Bargmann, C.I., and McIntire, S.L. (2003). A central role of the BK potassium channel in behavioral responses to ethanol in $C$. elegans. Cell 115, 655-666. Abstract Article

Davis, R.E. (1998). Neurophysiology of glutamatergic signalling and anthelmintic action in Ascaris suum: pharmacological evidence for a kainate receptor. Parasitol. 116, 471-486. Abstract Article

Dent, J.A., Davis, M.W., and Avery, L. (1997). avr-15 encodes a chloride channel subunit that mediates inhibitory glutamatergic neurotransmission and ivermectin sensitivity in Caenorhabditis elegans. EMBO J. 16, 5867-5879. Abstract Article

Dent, J.A., Smith, M.M., Vassilatis, D.K., and Avery, L. (2000). The genetics of ivermectin resistance in Caenorhabditis elegans. Proc. Natl. Acad. Sci. U. S. A. 97, 2674-2679. Abstract Article

Dillon, J., Andrianakis, I., Mould, R., Ient, B., Liu, W., James, C., O'Connor, V., and Holden-Dye, L. (2013). Distinct molecular targets including SLO-1 and gap junctions are engaged across a continuum of ethanol concentrations in Caenorhabditis elegans. FASEB J. 27, 4266-4278. Abstract Article

Driscoll, M., Dean, E., Reilly, E., Bergholz, E., and Chalfie, M. (1989). Genetic and molecular analysis of a Caenorhabditis elegans $\beta$-tubulin that conveys benzimidazole sensitivity. J. Cell Biol. 109, 2993-3003. Abstract Article

Ducray, P., Gauvry, N., Pautrat, F., Goebel, T., Fruechtel, J., Desaules, Y., Weber, S.S., Bouvier, J., Bagner, T., Froelich, O., and Kaminsky, R. (2008). Discovery of amino-acetonitrile derivatives, a new class of synthetic anthelmintic compounds. Biorg. Med. Chem. Lett. 18, 2935-2938. Abstract Article

Epe, C., and Kaminsky, R. (2013). New advancement in anthelmintic drugs in veterinary medicine. Trends Parasitol. 29, 129-134. Abstract Article 
Fleming, J.T., Squire, M.D., Barnes, T.M., Tornoe, C., Matsuda, K., Ahnn, J., Fire, A., Sulston, J.E., Barnard, E.A., Sattelle, D.B., and Lewis, J.A. (1997). Caenorhabditis elegans levamisole resistance genes lev-1, unc-29, and unc-38 encode functional nicotinic acetylcholine receptor subunits. J. Neurosci. 17, 5843-5857. Abstract

Fonseca-Salamanca, F., Martinez-Grueiro, M.M., and Martinez-Fernandez, A.R. (2003). Nematocidal activity of nitazoxanide in laboratory models. Parasitol. Res. 91, 321-324. Abstract Article

Francis, M.M., Evans, S.P., Jensen, M., Madsen, D.M., Mancuso, J., Norman, K.R., and Maricq, A.V. (2005). The Ror receptor tyrosine kinase CAM-1 is required for ACR-16-mediated synaptic transmission at the C. elegans neuromuscular junction. Neuron 46, 581-594. Abstract Article

Frooninckx, L., Van Rompay, L., Temmerman, L., Van Sinay, E., Beets, I., Janssen, T., Husson, S.J., and Schoofs, L. (2012). Neuropeptide GPCRs in C. elegans. Front. Endocrinol. 3, 167. Abstract

Gally, C., Eimer, S., Richmond, J.E., and Bessereau, J.L. (2004). A transmembrane protein required for acetylcholine receptor clustering in Caenorhabditis elegans. Nature 431, 578-582. Abstract Article

Garner, A.L., Gloeckner, C., Tricoche, N., Zakhari, J.S., Samje, M., Cho-Ngwa F., Lustigman, S., and Janda, K.D. (2011). Design, synthesis and biological activities of closantel analogues: structural promiscuity and its impact on Onchocerca volvulus. J. Med. Chem. 54, 3963-3972. Abstract Article

Geary, T.G. (2005). Ivermectin 20 years on: maturation of a wonder drug. Trends Parasitol. 21, 530-532. Abstract Article

Geary, T.G. (2012). Mechanism-based screening strategies for anthelmintic discovery. In Parasitic Helminths: Targets, Screens, Drugs and Vaccines, C.R. Caffrey, ed. (Weinheim, Germany: Wiley-VCH Verlag GmbH \& Co. KGaA), pp. 123-134. Abstract Article

Geary, T.G., and Maule, A.G., eds. (2010). Neuropeptide systems as targets for parasite and pest control. Adv. Exp. Med. Biol. 692, 1-230. Abstract

Geary T.G., Sangster, N.C., and Thompson, D.P. (1999). Frontiers in anthelmintic pharmacology. Vet. Parasitol. 84, 275-295. Abstract Article

Geary T.G., and Thompson, D.P. (2001). Caenorhabditis elegans: how good a model for veterinary parasites? Vet. Parasitol. 101, 371-386. Abstract Article

Gendrel, M., Rapti, G., Richmond, J.E., and Bessereau, J.L. (2009). A secreted complement-control-related protein ensures acetylcholine receptor clustering. Nature 461, 992-996. Abstract Article

Gilles, H.M., and Hoffman, P.S. (2002). Treatment of intestinal parasitic infections: a review of nitazoxanide. Trends Parasitol. 18, 95-97. Abstract Article

Gloeckner, C., Garner, A.L., Mersha, F., Oksov, Y., Tricoche, N., Eubanks, L.M., Lustigman, S., Kaufmann, G.F., and Janda, K.D. (2010). Repositioning of an existing drug for the neglected tropical disease Onchocerciasis. Proc. Natl. Acad. Sci. U. S. A. 107, 3424-3429. Abstract Article

Gottschalk, A., Almedom, R.B., Schedletzky, T., Anderson, S.D., Yates, J.R., and Schafer, W.R. (2005). Identification and characterization of novel nicotinic receptor-associated proteins in Caenorhabditis elegans. EMBO J. 24, 2566-2578. Abstract Article

Grauso, M., Culetto, E., Combes, D., Fedon, Y., Toutant, J-P., and Arpagaus, M. (1998). Existence of four acetylcholinesterase genes in the nematode Caenorhabditis elegans and Caenorhabditis briggsae. FEBS Lett. 424, 279-284. Abstract Article

Gravato-Nobre, M.J., Nicholas, H.R., Nijland, R., O'Rourke, D., Whittington, D.E., Yook, K.J., and Hodgkin, J. (2005). Multiple genes affect sensitivity of Caenorhabditis elegans to the bacterial pathogen Microbacterium nematophilum. Genetics 171, 1033-1045. Abstract Article 
Greenberg, RM. (2005). $\mathrm{Ca}^{2+}$ signalling, voltage-gated $\mathrm{Ca}^{2+}$ channels and praziquantel in flatworm neuromusculature. Parasitol. 131, S97-S108. Abstract Article

Greenwood, K., Williams, T., and Geary, T. (2005). Nematode neuropeptide receptors and their development as anthelmintic screens. Parasitology 131, S169-S177. Abstract Article

Griffiths, J.S., Haslam, S.M., Yang, T., Garczynski, S.F., Mulloy, B., Morris, H., Cremer, P.S., Dell, A., Adang, M.J., and Aroian, R.V. (2005). Glycolipids as receptors for Bacillus thuringiensis crystal toxin. Science 307, 922-925. Abstract Article

Guest, M., Bull, K., Walker, R.J., Amliwala, K., O'Connor, V., Harder, A., Holden-Dye, L., and Hopper, N.A. (2007). The calcium-activated potassium channel, SLO-1, is required for the action of the novel cyclo-octadepsipeptide anthelmintic, emodepside, in Caenorhabditis elegans. Int. J. Parasitol. 37, 1577-1588. Abstract Article

Haber, C.L., Heckaman, C.L., Li, G.P., Thompson, D.P., Whaley, H.A., and Wiley, V.H. (1991). Development of a mechanism of action-based screen for anthelmintic microbial metabolites with avermectin-like activity and isolation of milbemycin-producing Streptomyces strains. Antimicrob. Agents Chemother. 35, 1811-1817. Abstract Article

Halevi, S., McKay, J., Palfreyman, M., Yassin, L., Eshel, M., Jorgensen, E., and Treinin, M. (2002). The C. elegans ric-3 gene is required for maturation of nicotinic acetylcholine receptors. EMBO J. 21, 1012-1020. Abstract Article

Harder, A., and von Samson-Himmelstjerna, G. (2002). Cyclooctadepsipeptides- a new class of anthelmintically active compounds. Parasitol. Res. 88, 481-488. Abstract Article

Harrow, I.D., and Gration, K.A.F. (1985). Mode of action of the anthelmintics, morantel, pyrantel and levamisole on muscle cell membrane of the nematode, Ascaris suum. Pest. Sci. 16, 662-672. Article

Hawasli, A.H., Saifee, O., Liu, C., Nonet, M.L., and Crowder, C.M. (2004). Resistance to volatile anesthetics by mutations enhancing excitatory neurotransmitter release in Caenorhabditis elegans. Genetics 168, 831-843. Abstract Article

Hemphill, A., Mueller, J., and Keiser, J. (2006). Nitazoxanide, a broad spectrum thiazolide anti-effective agent for the treatment of gastrointestinal infections. Expert. Opin. Pharmacother. 7, 953-964. Abstract Article

Hernando, G., Berge, I., Rayes, D., and Bouzat, C. (2012). Contribution of subunits to Caenorhabditis elegans levamisole-sensitive nicotinic receptor function. Mol. Pharmacol. 82 550-560. Abstract Article

Hibbs, R.E., and Gouaux, E. (2011). Principles of activation and permeation in an anion-selective Cys-loop receptor. Nature 474, 54-60. Abstract Article

Holden-Dye, L., Crisford, A., Welz, C., von Samson-Himmelstjerna, G., Walker, R.J., and O'Connor, V. (2012). Worms take the slo lane: a perspective on the mode of action of emodepside. Invert. Neurosci. 12, 29-36. Abstract Article

Holden-Dye, L., Joyner, M., O'Connor, V., and Walker, R.J. (2013). Nicotinic acetylcholine receptors: a comparison of the nAChRs of Caenorhabditis elegans and parasitic nematodes. Parasitol. Int. 62, 606-615. Abstract Article

Holden-Dye, L., and Walker, R.J. (1990). Avermectin and avermectin derivatives are antagonists at the 4-aminobutyric acid (GABA) receptor on the somatic muscle cells of Ascaris; is this the site of anthelmintic action? Parasitol. 101, 265-271. Abstract Article

Holden-Dye, L., and Walker, R.J. (2006). Actions of glutamate and ivermectin on the pharyngeal muscle of Ascaridia galli: a comparative study with Caenorhabditis elegans. Int. J. Parasitol. 36, 395-402. Abstract Article

Holden-Dye, L., and Walker, R.J. (2011). Neurobiology of plant parasitic nematodes. Invert. Neurosci. 11, 9-19. Abstract Article 
Holden-Dye, L., and Walker, R.J. (2012). How relevant is Caenorhabditis elegans as a model for the analysis of parasitic nematode biology? In Parasitic Helminths: Targets, Screens, Drugs and Vaccines, C.R. Caffrey, ed. (Weinheim, Germany: Wiley-VCH Verlag GmbH \& Co. KGaA), pp. 23-41. Abstract

Hu, Y., and Aroian, R.V. (2012a). Bacterial pore-forming proteins as anthelmintics. Invert. Neurosci. 12, 37-41. Abstract Article

Hu, Y. and Aroian, R.V. (2012b). Promise of Bacillus thuringiensis crystal proteins as anthelmintics. In Parasitic Helminths: Targets, Screens, Drugs and Vaccines, C.R. Caffrey, ed. (Weinheim, Germany: Wiley-VCH Verlag GmbH \& Co. KGaA), pp. 267-281.

Hu, Y., Platzer, E.C., Bellier, A., and Aroian, R.V. (2010). Discovery of a highly synergistic anthelmintic combination that shows mutual hypersusceptibility. Proc. Natl. Acad. Sci. U. S. A. 107, 5955-5960. Abstract Article

Hu, Y., Xiao, S-H., and Aroian, R.V. (2009). The new anthelmintic tribendimidine is an L-type (levamisole and pyrantel) nicotinic acetylcholine receptor agonist. PLoS Negl. Trop. Dis. 3, e499. Abstract Article

Hu, C., Dillon, J., Kearn, J., Murray, C., O'Connor, V., Holden-Dye, L., and Morgan, H. (2013). NeuroChip: a microfluidic electrophysiological device for genetic and chemical biology screening of Caenorhabditis elegans adult and larvae. PLoS One 8, e64297. Abstract Article

Hulme, S.E., Shevkoplyas, S.S., and Samuel, A. (2008). Microfluidics: streamlining discovery in worm biology. Nat. Methods. 5, 589-90. Abstract Article

Husson, S.J., Clynen, E., Baggerman, G., Janssen, T., and Schoofs, L. (2006). Defective processing of neuropeptide precursors in Caenorhabditis elegans lacking proprotein convertase 2 (KPC-2/EGL-3): mutant analysis by mass spectrometry. J. Neurochem. 98, 1999-2012. Abstract Article

Jacob, T.C., and Kaplan, J.M. (2003). The EGL-21 carboxypeptidase E facilitates acetylcholine release at Caenorhabditis elegans neuromuscular junctions. J. Neurosci. 23, 2122-2130. Abstract

Jadhav, K.B., and Rajini, P.S. (2009). Evaluation of sublethal effects of dichlorvos upon Caenorhabditis elegans based on a set of end points of toxicity. J. Biochem. Mol. Toxicol. 23, 9-17. Abstract Article

James, C.E., and Davey, M.W. (2009). Increased expression of ABC transport proteins is associated with ivermectin resistance in the model nematode Caenorhabditis elegans. Int. J. Parasitol. 39, 213-220. Abstract Article

Janssen, I.J., Krucken, J., Demeler, J., and von Samson-Himmelstjerna, G. (2013). Caenorhabditis elegans: Modest increase of susceptibility to ivermectin in individual P-glycoprotein loss-of-function strains. Expt. Parasitol. 134, 171-177. Abstract Article

Jensen, M., Hoerndli, F.J., Brockie, P.J., Wang, R., Johnson, E., Maxfield, D., Francis, M.M., Madsen, D.M., and Maricq, A.V. (2012). Wnt signaling regulates acetylcholine receptor translocation and synaptic plasticity in the adult nervous system. Cell 149, 173-187. Abstract Article

Johnson, C.D., and Stretton, A.O. (1985). Localization of choline acetyltransferase within identified motoneurons of the nematode Ascaris. J. Neurosci. 5, 1984-1992. Abstract

Johnson, C.D., and Stretton, A.O. (1987). GABA-immunoreactivity in inhibitory motor neurons of the nematode Ascaris. J. Neurosci. 7, 223-235. Abstract

Jones, A.K., Buckingham, S.D., and Sattelle, D.B. (2005). Chemistry-to-gene screens in Caenorhabditis elegans. Nat. Rev. Drug. Discov. 4, 321-330. Abstract Article

Jospin, M., Qi, Y.B., Stawicki, T.M., Boulin, T., Schuske, K.R., Horvitz, H.R., Bessereau, J.L., Jorgensen, E.M., and Jin, Y. (2009). A neuronal acetylcholine receptor regulates the balance of muscle excitation and inhibition in Caenorhabditis elegans. PloS Biol. 7, e1000265. Abstract Article

Kagawa, H., Sugimoto, K., Matsumoto, H., Inoue, T., Imadzu, H., Takuwa, K., and Sakube, Y. (1995). Genome structure, mapping and expression of the tropomyosin gene tmy-1 of Caenorhabditis elegans. J. Mol. Biol. 251, 603-613. Abstract Article 
Kaminsky, R., Ducray, P., Jung, M., Clover, R., Rufener, L., Bouvier, J., Weber, S.S., Wenger, A., Wieland-Berghausen, S., Goebel, T, et al. (2008a). A new class of anthelmintics effective against drug-resistant nematodes. Nature 452, 176-180. Abstract Article

Kaminsky, R., Gauvry, N., Weber, S.S., Skripsky, T., Bouvier, J., Wenger, A., Schroeder, F., Desaules, Y., Hotz, R., Goebel, T., et al. (2008b). Identification of the amino-acetonitrile derivative monepantel (AAD 1566) as a new anthelmintic drug development candidate. Parasitol. Res. 103, 931-939. Abstract Article

Kaminsky, R., and Rufener, L. (2012). Monepantel: From discovery to mode of action. In Parasitic Helminths: Targets, Screens, Drugs and Vaccines, C.R. Caffrey, ed. (Weinheim, Germany: Wiley-VCH Verlag GmbH \& Co. KGaA), pp. 283-296. Abstract

Kao, C.Y., Los, F.C., Huffman, D.L., Wachi, S., Kloft, N., Husmann, M., Karabrahimi, V., Schwartz, J.L., Bellier, A., Ha, C., et al. (2011). Global functional analyses of cellular responses to pore-forming toxins. PloS Pathog. 7 , e1001314. Abstract Article

Karadzovska, D., Seewald, W., Browning, A., Smal, M., Bouvier, J., and Giraudel, J.M. (2009). Pharmacokinetics of monepantel and its sulfone metabolite, monepantel sulfone, after intravenous and oral administration in sheep. J. Vet. Pharmacol. Therap. 32, 359-367. Abstract Article

Kass, I.S., Wang, C.C., Walrond, J.P., and Stretton, A.O. (1980). Avermectin B1a, a paralyzing anthelmintic that affects interneurons and inhibitory motoneurons in Ascaris. Proc. Natl. Acad. Sci. U. S. A. 77, 6211-6215. Abstract Article

Kass, I.S., Larsen, D.A., Wang, C.C., and Stretton, A.O. (1982). Ascaris suum: differential effects of avermectin $\mathrm{B} 1 \mathrm{a}$ on the intact animal and neuromuscular strip preparations. Exp. Parasitol. 54, 166-174. Abstract Article

Kass, J., Jacob, T.C., Kim, P., and Kaplan, J.M. (2001). The EGL-3 proprotein convertase regulates mechanosensory responses of Caenorhabditis elegans. J. Neurosci. 21, 9265-9272. Abstract

Kawasaki, I., Jeong, M-H., Oh, B-K., and Shim, Y-H. (2010). Apigenin inhibits larval growth of Caenorhabditis elegans through DAF-16 activation. FEBS Lett. 584, 3587-3591. Abstract Article

Kearn, J., Dallière, N., and Dillon, J. (2013). Meeting report: 2012 Caenorhabditis elegans Neurobiology meeting, EMBL Advanced Training Centre, Germany. Invert Neurosci. 13, 85-90. Abstract Article

Kearn, J., Ludlow, E., Dillon, J. O’Connor, V., Holden-Dye, L. (2014). Fluensulfone is a nematicide with a mode of action distinct from anticholinesterases and macrocyclic lactones. Pestic. Biochem. Physiol. 109, 44-57. Abstract Article

Khakh, B.S., Proctor, W.R., Dunwiddie, T.V., Labarca, C., and Lester, H.A. (1999). Allosteric control of gating and kinetics at P2X(4) receptor channels. J. Neurosci. 19, 7289-7299. Abstract

Knaus, H.G., McManus, O.B., Lee, S.H., Schmalhofer, W.A., Garcia-Calvo, M., Helms, L.M., Sanchez, M., Giangiacomo, K., Reuben, J.P., Smith, A.B. $3^{\text {rd }}$, et al. (1994). Tremorgenic indole alkaloids potently inhibit smooth muscle high conductance calcium-activated potassium channels. Biochemistry 33, 5819-5828. Abstract Article

Knox, D.P. (2012). Proteases as vaccines against gastrointestinal nematode parasites of sheep and cattle. In Parasitic Helminths: Targets, Screens, Drugs and Vaccines, C.R. Caffrey, ed. (Weinheim, Germany: Wiley-VCH Verlag GmbH \& Co. KGaA), pp. 399-420. Abstract

Kotze, A.C., O'Grady, J., Gough, J.M., Pearson, R., Bagnall, N.H., Kemp, D.H., and Akhurst, R.J. (2005). Toxicity of Bacillus thuringiensis to parasitic and free-living life-stages of nematode parasites of livestock. Int. J. Parasitol. 35, 1013-1022. Abstract Article

Krause, R.M., Buisson, B., Bertrand, S., Corringer, P.J., Galzi, J.L., Changeux, J.P., and Bertrand, D. (1998). Ivermectin: a positive allosteric effector of the $\alpha 7$ neuronal nicotinic acetylcholine receptor. Mol. Pharmacol. 53, 283-294. Abstract 
Krucken, J., Harder, A., Jeschke, P., Holden-Dye, L., O’Connor, V., Welz, C., and von Samson-Himmelstjerna, G. (2012). Anthelmintic cyclooctadepsipeptides: complex in structure and mode of action. Trends Parasitol. 28, 385-394. Abstract Article

Kwa, M.S., Veenstra, J.G., and Roos, M.H. (1994). Benzimidazole resistance in Haemonchus contortus is correlated with a conserved mutation at amino acid 200 in beta-tubulin isotype. Mol. Biochem. Parasitol. 63, $299-303$. Abstract

Kwa, M.S., Veenstra, J.G., Van Dijk, M., and Roos, M.H. (1995). Beta-tubulin genes from the parasitic nematode Haemonchus contortus modulate drug resistance in Caenorhabditis elegans. J. Mol. Biol. 246, 500-510. Abstract Article

Lacey, E. (1990). Mode of action of benzimidazoles. Parasitol. Today 6, 112-115. Abstract Article

Laing, R., Kikuchi, T., Martinelli, A., Tsai, I.J., Beech, R.N., Redman, E., Holroyd, N., Bartley, D.J., Beasley, H., Britton, C., et al. (2013). The genome and transcriptome of Haemonchus contortus, a key model parasite for drug and vaccine discovery. Genome Biol. 14, R88. Abstract Article

Larsen, M.J., Ruiz- Lancheros, E., Williams, T., Lowery, D.E., Geary, T.G., and Kubiak, T.M. (2013). Functional expression and characterization of the $C$. elegans G-protein-coupled FLP-2 Receptor (T19F4.1) in mammalian cells and yeast. Int. J. Parasitol. Drugs Drug Resist. 3, 1-7. Abstract Article

Laughton, D.L., Lunt, G.G., and Wolstenholme, A.J. (1997). Reporter gene constructs suggest that the Caenorhabditis elegans avermectin receptor $\beta$-subunit is expressed solely in the pharynx. J. Exp. Biol. 200, 1509-1514. Abstract

Lee, B.H., Clothier, M.F., Dutton, F.E., Nelson, S.J., Johnson, S.S., Thompson, D.P., Geary, T.G., Whaley, H.D., Haber, C.L., Marshall, V.P., et al. (2002). Marcfortine and paraherquamide class of anthelmintics: discovery of PNU-141962. Curr. Top. Med. Chem. 2, 779-793. Abstract Article

Lee, Y-U., Kawasaki, I., Lim, Y., Oh, W-S., Pail, Y-K., and Shim, Y-H. (2008). Inhibition of developmental processes by flavone in Caenorhabditis elegans and its application to the pinewood nematode, Bursaphelenchus xylophilus. Mol. Cells 26, 171-174. Abstract

Levandoski, M.M., Robertson, A.P., Kuiper, S., Qian, H., and Martin, R.J. (2005). Single-channel properties of Nand L-subtypes of acetylcholine receptor in Ascarus suum. Int. J. Parasitol. 35, 925-934. Abstract Article

Lewis, J.A., Gehman, E.A., Baer, C.E., and Jackson, D.A. (2013). Alterations in gene expression in Caenorhabditis elegans associated with organophosphate pesticide intoxication and recovery. BMC Genomics 14, 291. Abstract Article

Lewis, J.A., Szilagyi, M., Gehman, E., Dennis, W.E., and Jackson, D.A. (2009). Distinct patterns of gene and protein expression elicited by organophosphorus pesticides in Caenorhabditis elegans. BMC Genomics $10,202$. Abstract Article

Lewis, J.A., Wu, C.H., Berg, H., and Levine, J.H. (1980a). The genetics of levamisole resistance in the nematode Caenorhabditis elegans. Genetics 95, 905-928. Abstract

Lewis, J.A., Wu, C.H., Levine, J.H., and Berg, H. (1980b). Levamisole-resistant mutants of the nematode Caenorhabditis elegans appear to lack pharmacological acetylcholine receptors. Neuroscience 5, 967-989. Abstract Article

Lewis, J.A., Elmer, J.S., Skimming, J., McLafferty, S., Fleming, J., and McGee, T. (1987). Cholinergic receptor mutants of the nematode Caenorhabditis elegans. J. Neurosci. 7, 3059-3071. Abstract

Li, C. (2005). The ever-expanding neuropeptide gene families in the nematode Caenorhabditis elegans. Parasitol. 131, S109-S127. Article

Li, C. and Kim, K. (2010). Neuropeptide gene families in Caenorhabditis elegans. Ad. Exp. Med. Biol. 692, 98-137. Abstract Article 
Liu, P., Martin, R.J., and Dong, L. (2013). Micro-electro-fluidic grids for nematodes: a lens-less, image-sensor-less approach for on-chip tracking of nematode locomotion. Lab Chip. 13, 650-661. Abstract Article

Lockery, S.R., Hulme, S.E., Roberts, W.M., Robinson, K.J., Laromaine, A., Lindsay, T.H., Whitesides, G.M., and Weeks, J.C. (2012). A microfluidic device for whole-animal drug screening using electrophysiological measures in the nematode C. elegans. Lab Chip 12, 2211-2220. Abstract Article

Lynagh, T., and Lynch, J.W. (2012). Molecular mechanisms of Cys-loop ion channel receptor modulation by ivermectin. Front. Mol. Neurosci. 5, 60. Abstract Article

Marks, N.J., and Maule, A.G. (2010). Neuropeptides in helminths: occurrence and distribution. Adv. Exp. Med. Biol. 692, 49-77. Review. Abstract Article

Marroquin, L.D., Elyassnia, D., Griffitts, J.S., Feitelson, J.S., and Aroian, R.V. (2000). Bacillus thuringiensis (Bt) toxin susceptibility and isolation of resistance mutants in the nematode Caenorhabditis elegans. Genetics 155, 1693-1699. Abstract

Martin, R.J. (1985). gamma-Aminobutyric acid- and piperazine-activated single-channel currents from Ascaris suum body muscle. Br. J. Pharmacol. 84, 445-461. Abstract Article

Martin, R.J., Buxton, S.K., Neveu, C., Charvet, C.L., and Robertson, A.P. (2012a). Emodepside and SLO-1 potassium channels: a review. Expt. Parasitol. 132, 40-46. Abstract Article

Martin, R.J., Robertson, A.P., Buxton, S.K., Beech, R.N., Charvet, C.L., and Neveu, C. (2012b). Levamisole receptors: a second awakening. Trends Parasitol. 28, 289-296. Abstract Article

Martin, R.J., Verma, S., Levandoski, M., Clark, C.L., Qian, H., Stewart, M., and Robertson, A.P. (2005). Drug resistance and neurotransmitter receptors of nematodes: recent studies on the mode of action of levamisole. Parasitol. 131, S71-S84. Abstract Article

Maryon, E.B., Coronado, R., and Anderson, P. (1996). unc-68 encodes a ryanodine receptor involved in regulating C. elegans body-wall muscle contraction. J. Cell Biol. 134, 885-893. Abstract Article

Miller K.G., Alfonso , A., Nguyen, M., Crowell, J.A., Johnson, C.D., and Rand, J.B. (1996). A genetic selection for Caenorhabditis elegans synaptic transmission mutants. Proc. Natl. Acad. Sci. U. S. A. 93, 12593-12598. Abstract Article

Miltsch, S.M., Krucken, J., Demeler, J., Ramunke, S., Harder, A., and Samson-Himmelstjerna, G. (2013). Interactions of anthelmintic drugs in Caenorhabditis elegans neuro-muscular ion channel mutants. Parasitol. Int. 62, 591-598. Abstract Article

Mitreva, M., Blaxter, M.L., Bird, D.M., and McCarter, J.P. (2005). Comparative genomics of nematodes. Trends Genet. 21, 573-581. Abstract Article

McVeigh, P., Atkinson, L., Marks, N.J., Mousley, A., Dalzell, J.J., Sluder, A., Hammerland, L., and Maule, A.G. (2012). Parasite neuropeptide biology: Seeding rational drug target selection? Int. J. Parasitol. Drugs Drug Resist. 2, 76-91. Abstract Article

McVeigh, P., Leech, S., Mair, G.R., Marks, N.J., Geary, T.G., and Maule A.G. (2005). Analysis of FMRFamide-like peptide (FLP) diversity in phylum Nematoda. Int. J. Parasitol. 35, 1043-1060. Abstract Article

Moerman, D.G., Benian, G.M., Barstead, R.J., Schriefer, L.A., and Waterston, R.H. (1988). Identification and intracellular localization of the unc-22 gene product of Caenorhabditis elegans. Genes Dev. 2, 93-105. Abstract Article

Mongan, N.P., Jones, A.K., Smith, G.R., Sansom, M.S., and Sattelle, D.B. (2002). Novel $\alpha 7-$ like nicotinic acetylcholine receptor subunits in the nematode Caenorhabditis elegans. Protein Sci. 11, 1162-1171. Abstract Article 
Moreno, Y., Nabhan, J.F., Solomon, J., Mackenzie, C.D., and Geary, T.G. (2010). Ivermectin disrupts the function of the excretory-secretory apparatus in microfilariae of Brugia malayi. Proc. Natl. Acad. Sci. U. S. A. 107, $20120-5$. Abstract Article

Murray, L., Geldhof, P., Clark, D., Knox, D.P., and Britton, C. (2007). Expression and purification of an active cysteine protease of Haemonchus contortus using Caenorhabditis elegans. Int. J. Parasitol. 37, 1117-1125. Abstract Article

Neveu, C., Charvet, C.L., Fauvin, A., Cortet, J., Beech, R.N., and Cabaret, J. (2010). Genetic diversity of levamisole receptor subunits in parasitic nematode species and abbreviated transcripts associated with resistance. Pharmacogenet. Genomics 20, 414-425. Abstract

Nguyen, M., Alfonso, A., Johnson, C.D., and Rand, J.B. (1995). Caenorhabditis elegans mutants resistant to inhibitors of acetylcholinesterase. Genetics 140, 527-535. Abstract

Oka, Y., Shuker, S., and Tkachi, N. (2009). Nematicidal efficacy of MCW-2, a new nematicide of the fluoroalkenyl group, against the root-knot nematode Meloidogyne javanica. Pest Manag. Sci. 65, 1082-1089. Abstract Article

Oka, Y., Shuker, S., and Tkachi, N. (2012). Systemic nematicidal activity of fluensulfone against the root-knot nematode Meloidogyne incognita on pepper. Pest Manag. Sci. 68, 268-75. Abstract Article

Olesen, S.P., Munch, E., Moldt, P., and Drejer, J. (1994). Selective activation of $\mathrm{Ca}^{2+}$-dependent $\mathrm{K}^{+}$channels by novel benzimidazolone. Eur.J. Pharmacol. 251, 53-59. Abstract Article

Olliaro, P., Seiler, J., Kuesel, A., Horton, J., Clark, J.N., Don, R. and Keiser, J. (2011) Potential drug development candidates for human soil-transmitted helminthiases. PLoS Negl. Trop. Dis. 5, e1138. Abstract Article

Osei-Atweneboana, M.Y., Awadzi, K., Attah, S.K., Boakye, D.A., Gyapong, J.O. and Prichard, R.K. (2011). Phenotypic evidence of emerging ivermectin resistance in Onchocerca volvulus. PloS Negl. Trop. Dis. 5 , e998. Abstract Article

Osei-Atweneboana, M.Y., Eng, J.K., Boakye, D.A., Gyapong, J.O., and Prichard, R.K. (2007). Prevalence and intensity of Onchocerca volvulus infection and efficacy of ivermectin in endemic communities in Ghana: a two-phase epidemiological study. Lancet 369, 2021-9. Abstract Article

Pemberton, D.J., Franks, C.J., Walker, R.J., and Holden-Dye, L. (2001). Characterization of glutamate-gated chloride channels in the pharynx of wild-type and mutant Caenorhabditis elegans delineates the role of the subunit GluCl- $\alpha 2$ in the function of the native receptor. Mol. Pharmacol. 59, 1037-1043. Abstract

Portillo, V., Jagannathan, S., and Wolstenholme, A.J. (2003). Distribution of glutamate-gated chloride channel subunits in the parasitic nematode Haemonchus contortus. J. Comp. Neurol. 462, 213-222. Abstract Article

Qian, H., Martin, R.J., and Robertson, A.P. (2006). Pharmacology of N-, L-, and B-subtypes of nematode nAChR resolved at the single-channel level in Ascaris suum. FASEB J. 20, 2606-2608. Abstract Article

Qian, H., Robertson, A.P., Powell-Coffman, J.A., and Martin, R.J. (2008). Levamisole resistance resolved at the single-channel level in Caenorhabditis elegans. FASEB J. 22, 3247-3254. Abstract Article

Rana, A.K., and Misra-Bhattacharya, S. (2013). Current drug targets for helminthic disease. Parasitol. Res. 112, 1819-1831. Abstract Article

Rand, J.B., and Johnson, C.D. (1995). Genetic pharmacology: interactions between drugs and gene products in Caenorhabditis elegans. Methods Cell Biol. 48, 187-204. Abstract Article

Rapti, G., Richmond, J.E., and Bessereau, J.L. (2011). A single immunoglobulin-domain protein required for clustering acetylcholine receptors in C. elegans. EMBO J. 30, 706-718. Abstract Article

Rayes, D., Flamini, M., Hernando, G., and Bouzat, C. (2007). Activation of single nicotinic receptor channels from Caenorhabditis elegans. Mol. Pharmacol. 71, 1407-1415. Abstract Article 
Richmond, J.E. and Jorgensen, E.M. (1999). One GABA and two acetylcholine receptors function at the C. elegans neuromuscular junction. Nature Neurosci. 2, 791-797 Abstract Article

Robertson, A.P., Clark, C.L., Burns, T.A., Thompson, D.P., Geary, T.G., Trailovic, S.M., and Martin, R.J. (2002). Paraherquamide and 2-deoxy-paraherquamide distinguish cholinergic receptor subtypes in Ascaris muscle. J. Pharmacol. Exp. Ther. 302, 853-860. Abstract Article

Robertson, B. (1989). Actions of anaesthetics and avermectin on GABAA chloride channels in mammalian dorsal root ganglion neurons. Br. J. Pharmacol. 98, 167-176. Abstract Article

Rufener, L., Baur, R., Kaminsky, R., Maser, P., and Sigel, E. (2010a). Monepantel allosterically activates DEG-3/DES-2 channels of the gastrointestinal nematode Haemonchus contortus. Mol. Pharmacol. 78, 895-902. Abstract Article

Rufener, L., Keiser, J., Kaminsky, R., Maser, P., and Nilsson, D. (2010b). Phylogenomics of ligand-gated ion channels predicts monepantel effect. PLoS Pathog. 6, e1001091. Abstract Article

Rufener, L., Maser, P., Roditi, I., and Kaminsky, R. (2009). Haemonchus contortus acetylcholine receptors of the DEG-3 subfamily and their role in sensitivity to monepantel. PLoS Pathog. 5, e1000380. Abstract Article

Ruiz-Lancheros, E., Viau, C., Walter, T.N., Francis, A., and Geary, T.G. (2011). Activity of novel nicotinic anthelmintics in cut preparations of Caenorhabditis elegans. Int. J. Parasitol. 41, 455-461. Abstract Article

Saeger, B., Schmitt-Wrede, H.P., Dehnhardt, M., Benten, W.P., Krucken, J., Harder, A., von Samson-Himmelstjerna, G., Wiegand, H., and Wunderlich, F. (2001). Latrophilin-like receptor from the parasitic nematode Haemonchus contortus as target for the anthelmintic depsipeptide PF1022A. FASEB J. 15, $1332-1334$. Abstract

Sager, H., Bapst, B., Strehlau, G.A., and Kaminsky, R. (2012). Efficacy of monepantel, derquantel and abamectin against adult stages of a multi-resistant Haemonchus contortus isolate. Parasitol Res. 111, 2205-2207. Abstract Article

Salkoff, L., Butler, A., Ferreira, G., Santi, C., and Wei A. (2006). High-conductance potassium channels of the SLO family. Nat. Rev. Neurosci. 7, 921-931. Abstract Article

Saunders, G.I., Wasmuth, J.D., Beech, R., Laing, R., Hunt, M., Naghra, H., Cotton, J.A., Berriman, M., Britton, C., and Gilleard, J.S. (2013). Characterization and comparative analysis of the complete Haemonchus contortus $\beta$-tubulin gene family and implications for benzimidazole resistance in strongylid nematodes. Int. J. Parasitol. 43, 465-475. Abstract

Schaeffer, J.M., Blizzard, T.A., Ondeyka, J., Goegelman, R., Sinclair, P.J., and Mrozik, H. (1992). $\left[{ }^{3} \mathrm{H}\right]$-Paraherquamide binding to Caenorhabditis elegans. Studies on a potent new anthelmintic agent. Biochem. Pharmacol. 43, 679-684. Abstract

Schwarz, E.M., Korhonen, P.K., Campbell, B.E., Young, N.D., Jex, A.R., Jabbar, A., Hall, R.S., Mondal, A., Howe, A.C., Pell, J., et al. (2013). The genome and developmental transcriptome of the strongylid nematode Haemonchus contortus. Genome Biol. 14, R89. Abstract Article

Selkirk, M.E., Lazari, O., and Matthews, J.B. (2005). Functional genomics of nematode acetylcholinesterases. Parasitol. 131, S3-S18. Abstract Article

Shan, Q., Haddrill, J.L., and Lynch, J.W. (2001). Ivermectin, an unconventional agonist of the glycine receptor chloride channel. J. Biol. Chem. 276, 12556-12564. Abstract Article

Shteingauz, A., Cohen, E., Biala, Y., and Treinin, M. (2009). The BTB-MATH protein BATH-42 interacts with RIC-3 to regulate maturation of nicotinic acetylcholine receptors. J. Cell Sci. 122, 807-812. Abstract Article

Sieburth, D., Ch'ng, Q., Dybbs, M., Tavazoie, M., Kennedy, S., Wang, D., Dupuy, D., Rual, J.F., Hill, D.E., Vidal, M., Ruvkun, G., and Kaplan, J.M. (2005). Systematic analysis of genes required for synapse structure and function. Nature 436, 510-517. Abstract Article 
Simon, D.J., Madison, J.M., Conery, A.L., Thompson-Peer, K.L., Soskis, M., Ruvkun, G.B., Kaplan, J.M., and Kim, J.K. (2008). The microRNA miR-1 regulates a MEF-2-dependent retrograde signal at neuromuscular junctions. Cell 133, 903-915. Abstract Article

Skuce, P.J., and Fairweather, I. (1990). The effect of the hydrogen ionophore closantel upon the pharmacology and ultrastructure of the adult liver fluke Fasciola hepatica. Parasitol Res. 76, 241-250. Abstract Article

Sluder, A., Shah, S., Cassayre, J., Clover, R., Maienfisch, P., Molleyres, L.P., Hirst, E.A., Flemming, A.J., Shi, M., Cutler, P., et al. (2012). Spiroindolines identify the vesicular acetylcholine transporter as a novel target for insecticide action. PLoS One. 7, e34712. Abstract Article

Stirman, J.N., Brauner, M., Gottschalk, A., and Lu, H. (2010). High-throughput study of synaptic transmission at the neuromuscular junction enabled by optogenetics and microfluidics. J. Neurosci. Methods. 191, 90-93. Abstract Article

Stringham, E.G., and Candido, E.P.M. (1994). Transgenic hsp16-lacZ strains of the soil nematode Caenorhabditis elegans as biological monitors of environmental stress. Environ. Toxicol. Chem. 13, 1211-1220. Article

Thomas, H. (1979). The efficacy of amidantel, a new anthelmintic, on hookworms and ascarids in dogs. Tropenmed. Parasitol. 30, 404-408. Abstract

Touroutine, D., Fox, R.M., von Stetina, S.E., Burdina, A., Miller III, D.M., and Richmond, J.E. (2005). acr-16 encodes an essential subunit of the levamisole-resistant nicotinic receptor at the Caenorhabditis elegans neuromuscular junction. J. Biol. Chem. 280, 27013-27021. Abstract

Towers, P.R., Edwards, B., Richmond, J.E., and Sattelle, D.B. (2005). The Caenorhabditis elegans lev-8 gene encodes a novel type of nicotinic acetylcholine receptor $\alpha$ subunit. J. Neurochem. 93, 1-9. Abstract

Tritten, L., Silbereisen, A., and Keiser, J. (2012). Nitazoxanide: In vitro and in vivo drug effects against Trichuris muris and Ancylostoma celanicum, alone or in combination. Int. J. Parasitol. Drugs Drug Resist. 2, 98-105. Abstract

Valli, M., Danuello, A., Pivatto, M., Saldana, J., Heinzen, H., Dominguez, L., Campos, V.P., Marqui, S.R., Young, M.C., Viegas, C. Jr., et al. (2011). Anticholinesterasic, nematostatic and anthelmintic activities of pyridinic and pyrazinic compounds. Curr. Med. Chem. 18, 3423-3430. Abstract

Vinuela, A., Snoek, L.B., Riksen, J.A.G., and Kammenga, J.E. (2010). Genome-wide gene expression analysis in response to organophorus pesticide chlorpyrifos and diazinon in C. elegans. PLoS ONE 5, e12145. Abstract

Waggoner, L.E., Dickinson, K.A., Poole, D.S., Tabuse, Y., Miwa, J., and Schafer, W.R. (2000). Long-term nicotine adaptation in Caenorhabditis elegans involves PCK-dependent changes in nicotinic receptor abundance. J. Neurosci. 20, 8802-8811. Abstract

Wang, Z.W., Saifee, O., Nonet M.L., and Salkoff L. (2001). SLO-1 potassium channels control quantal content of neurotransmitter release at the $C$. elegans neuromuscular junction. Neuron 32, 867-881. Abstract

Wei, J.Z., Hale, K., Carta, L., Platzer, E., Wong, C., Fang, S.C., and Aroian, R.V. (2003). Bacillus thuringiensis crystal proteins that target nematodes. Proc. Natl. Acad. Sci. U. S. A. 100, 2760-2765. Abstract

Welz, C., Kruger, N., Schnierderjans, M., Miltsch, S.M., Krucken, J., Guest, M., Holden-Dye, L., Harder, A., and von Samson-Himmelstjema, G. (2011). SLO-1 channels of parasitic nematodes reconstitute locomotor behaviour and emodepside sensitivity in Caenorhabditis elegans slo-1 loss-of-function mutants. PLoS Pathog. 7, e1001330. Abstract

Wenick, A.S., and Hobert, O. (2004). Genomic cis-regulatory architecture and trans-acting regulators of a single interneuron-specific gene battery in C. elegans. Dev. Cell 6, 757-770. Abstract Article

Willson, J., Amliwala, K., Harder, A., Holden-Dye, L., and Walker, R.J. (2003). The effect of the anthelmintic emodepside at the neuromuscular junction of the parasitic nematode Ascaris suum. Parasitol. 126, 79-86. Abstract Article 
Willson, J., Amliwala, K., Davis, A., Cook, A., Cuttle, M.F., Kriek, N., Hopper, N.A., O'Connor, V., Harder, A., Walker, R.J., and Holden-Dye, L. (2004). Latrotoxin receptor signaling engages the UNC-13-dependent vesicle-priming pathway in C. elegans. Curr. Biol. 14, 1374-1379. Abstract

Wolstenholme, A.J. (2011). Ion channels and receptor as targets for the control of parasitic nematodes. Int. J. Parasitol. Drugs Drug Resist. 1, 2-13. Abstract Article

Wolstenholme, A.J., Fairweather, I., Prichard, R., von Samson-Himmelstjerna, G., and Sangster, N.C. (2004). Drug resistance in veterinary helminths. Trends Parasitol. 20, 469-476. Abstract Article

Woods, D.J., Maeder, S.J., Robertson, A.P., Martin, R.J., Geary, T.G., Thompson, D.P., Johnson, S.S., and Conder, G.A. (2012). Discovery, Mode of Action, and Commercialization of Derquantel. In Parasitic Helminths: Targets, Screens, Drugs and Vaccines, C.R. Caffrey, ed. (Weinheim, Germany: Wiley-VCH Verlag GmbH \& Co. KGaA), pp. 297-307.

Xiao, S-H., Hui-Ming, W., Tanner, M., Utzinger, J., and Chong, W. (2005). Tribendimidine: a promising, safe and broad-spectrum anthelmintic agent from China. Acta Tropica 94, 1-14. Abstract

Xiao, S-H., Utzinger, J., Tanner, M., Keiser, J., and Xue, J. (2013). Advances with the Chinese anthelmintic drug tribendimidine in clinical trials and laboratory investigations. Acta Trop. 126, 115-126. Abstract Article

Xu, X., and Kim, S.K. (2011). The early bird catches the worm: new technologies for the Caenorhabditis elegans toolkit. Nat. Rev. Genet. 12, 793-801. Abstract

Yates, D.M., Portillo, V., and Wolstenholme, A.J. (2003). The avermectin receptors of Haemonchus contortus and Caenorhabditis elegans. Int. J. Parasitol. 33, 1183-1193. Abstract Article

Yoon, Y.A., Kim, H., Lim, Y., and Shim, Y.H. (2006). Relationships between the larval growth inhibition of Caenorhabditis elegans by apigenin derivatives and their structures. Arch. Pharm. Res. 29, 582-586. Abstract

Zakharov, S.I., Morrow, J.P., Liu, G., Yang, L., and Marx, S.O. (2005). Activation of the BK (SLO-1) potassium channel by mallotoxin. J. Biol. Chem. 280, 30882-30887. Abstract

Zahner, H., Taubert, A., Harder, A., and von Samson-Himmelstjerna, G. (2001). Filaricidal efficacy of anthelmintically active cyclodepsipeptides. Int. J. Parasitol. 31, 1515-1522. Abstract Article

Zheng, Y., Hirschberg, B., Yuan, J., Wang, A.P., Hunt, D.C., Ludmerer, S.W., Schmatz, D.M., and Cully, D.F. (2002). Identification of two novel Drosophila melanogaster histamine-gated chloride channel subunits expressed in the eye. J. Biol. Chem. 277, 2000-2005. Abstract Article

Zinser, E.W., Wolfe, M.L., Alexander-Bowman, S.J., Thomas, E.M., Davis, J.P., Groppi, V.E., Lee, B.H., Thompson, D.P., and Geary, T.G. (2002). Anthelmintic paraherquamides are cholinergic antagonists in gastrointestinal nematodes and mammals. J. Vet. Pharmacol. Ther. 25, 241-250. Abstract Article 